This item was submitted to Loughborough's Research Repository by the author.

Items in Figshare are protected by copyright, with all rights reserved, unless otherwise indicated.

\title{
Pyrene-cored blue-light emitting [4]helicenes: synthesis, crystal structures, and photophysical properties
}

\section{PLEASE CITE THE PUBLISHED VERSION}

http://dx.doi.org/10.1039/c3ob27320b

\section{PUBLISHER}

(c) Royal Society of Chemistry

\section{VERSION}

AM (Accepted Manuscript)

\section{PUBLISHER STATEMENT}

This work is made available according to the conditions of the Creative Commons Attribution-NonCommercialNoDerivatives 4.0 International (CC BY-NC-ND 4.0) licence. Full details of this licence are available at: https://creativecommons.org/licenses/by-nc-nd/4.0/

\section{LICENCE}

CC BY-NC-ND 4.0

\section{REPOSITORY RECORD}

Hu, Jian-Yong, Arjun Paudel, Nobuyuki Seto, Xing Feng, Masanao Era, Taisuke Matsumoto, Junji Tanaka, Mark R.J. Elsegood, Carl Redshaw, and Takehiko Yamato. 2019. "Pyrene-cored Blue-light Emitting [4]helicenes: Synthesis, Crystal Structures, and Photophysical Properties”. figshare. https://hdl.handle.net/2134/18307. 


\title{
Organic \&

\section{Pyrene-cored blue-light emitting [4]helicenes: Synthesis, crystal structures, and photophysical properties}

\author{
Jian-Yong Hu, ${ }^{a, b}$ Arjun Paudel, ${ }^{a}$ Nobuyuki Seto, ${ }^{a}$ Xing Feng, ${ }^{a}$ Masanao Era, ${ }^{a}$ Taisuke Matsumoto,,${ }^{c}$ Junji \\ Tanaka, ${ }^{c}$ Mark R. J. Elsegood, ${ }^{d}$ Carl Redshaw, ${ }^{e}$ and Takehiko Yamato* ${ }^{a}$
}

\author{
Received (in $X X X, X X X) X$ th $X X X X X X X X X 20 X X$, Accepted $X$ th $X X X X X X X X X 20 X X$
}

DOI: 10.1039/c1ob00000x

The synthesis, crystal structures and photophysical properties of two types of pyrene-cored blue-light emitting [4]helicenes (7 and 9) are reported. The chemical structures of all synthesized compounds were fully confirmed by their ${ }^{1} \mathrm{H}$ and ${ }^{13} \mathrm{C}$ NMR spectra, mass spectroscopy as well as elemental analysis.

${ }_{10}$ Single-crystal X-ray analysis of these [4]helicenes revealed that there are two types of laterally naphthalene annulated helical architectures, which are clearly influenced by the difference of the Rsubstituents. The photophysical properties of the [4]helicenes (7 and 9) were fully investigated in both solution and film, along with the pre-cyclization products, 4,9- and 4,10-bis(phenylethenyl)pyrenes (6 and 8). Notable optical features were obtained in these compounds, that make them might be promising ${ }_{5}$ candidates for several important applications in modern electronic and optoelectronic devices, such as blue emitters in organic light-emitting devices (OLEDs), or as models for further exploring the development of a new generation of organic materials base on pyrene.

\section{Introdution}

Helicenes and helicene-like molecules have recieved much 20 consideration as academic curiosities because of their twisted shape which results from the repulsive steric overlap of the terminal aromatic nuclei. ${ }^{1}$ Due to their unique structural properties, like ortho-condensed aromatic rings, which have a powerful, inherently chiral, chromophore and the possibility of 25 electronic interaction, ${ }^{2}$ the scientific interests of the helicenes are now revising. Recently, these helically shaped molecules have been found many important applications, such as useful component in chiral discotic liquid crystalline materials, ${ }^{3}$ building

$30^{a}$ Department of Applied Chemistry, Faculty of Science and Engineering, Saga University, Honjo machi 1, Saga-shi, Saga, Japan

E-mail: yamatot@cc.saga-u.ac.jp; Fax:+81-952-288548

${ }^{b}$ Department of Organic Device Engineering, Yamagata University, Yonezawa, Yamagata, 992-8510, Japan

35 E-mail: hujianyong@yz.yamagata-u.ac.jp; Fax: +81-238-263412 ${ }^{c}$ Institute of Material Chemistry and Engineering, Kyushu University, 61, Kasugakoen, Kasuga 816-8580, Japan

${ }^{d}$ Chemistry Department, Loughborough, University, Loughborough, Leicestershire, LE11 3TU, UK, LE11 3TU

${ }_{40}{ }^{e}$ Department of Chemistry, The University of Hull, UK, HU6 7RX $\dagger$ Electronic supplementary information (ESI) available: ${ }^{1} \mathrm{H} /{ }^{13} \mathrm{C}$ NMR spectra of $\mathbf{6 a - c}, 7 \mathbf{a}-\mathbf{d}, \mathbf{8}$ and $\mathbf{9}$, TGA curves of $\mathbf{7 a - c}$ and $\mathbf{9}$, packing diagram of $\mathbf{7 b}, \mathbf{7 c}$ and $\mathbf{9}$, emission spectra of $\mathbf{7 a - c}$ and $\mathbf{9}$ in $1 \mathrm{wt} \%$-doped into PMMA films, cyclic voltammogram (CV) of $\mathbf{7 a - c}$ and $\mathbf{9}$, and

45 summary of crystal data of $\mathbf{7 b}, \mathbf{7 c}$ and $\mathbf{9}$. CCDC reference numbers 778372 (7b), 870212 (7c) and 870213 (9) . For ESI and crystallographic data in CIF format see DOI: $10.1039 / \mathrm{c} 10 b 00000 \mathrm{x} /$ blocks for helical conjugated polymers, ${ }^{4}$ sensors $^{5}$ and dyes ${ }^{5}$ in molecular recognitions, and more fascinatingly as catalysts or ${ }_{50}$ ligands in asymmetric synthesis, ${ }^{6}$ and very recently, as blue emitters in OLEDs. ${ }^{7}$ Thus, there is a sudden surge of interest for exploring novel helicenes with unique optoelectronic properties through new synthetic protocols.

Much recent efforts have been devoted to the development of 55 new synthetic procedures, and the procedures are now continuously improving. ${ }^{1,8}$ Classical available methods for the synthesis of the helicenes are of the Friedel-Crafts approach to fuse rings reported by Newman and co-worker ${ }^{1 \mathrm{a}}$ and the photochemically mediated cyclization of stilbene derivatives ${ }_{60}$ developed by Martins and co-workers. ${ }^{8 b, 9}$ The two methods have recently been optimized and widely applied. Although many $[n]$ helicenes consisting of fused aromatic rings, including benzene, ${ }^{10}$ thiophene, ${ }^{11}$ and benzothiophene, ${ }^{12}$ have previously been reported, to our knowledge, there have only a few reports ${ }^{13}$ ${ }_{65}$ on the $[n]$ helicenes, in which a large $\pi$-conjugated polycyclic aromatic hydrocarbons (PAHs) core, such as pyrene, was used to construct the helical structures. Recently, as a part of our research program on the construction of the pyrene-cored $\pi$-conjugated $[n]$ helicenes, we successfully prepared a series of 4,5-naphthalene 70 annulated pyrenes ${ }^{14}$ by using an oxidative intramolecular photocyclization, in which the [4]helicene ${ }^{15}$ structures are contained. Thus, there is a continuous interest to extend more higher members of helicene frameworks, such as to prepare new $[n]$ helicene motifs around the pyrene core through novel 75 procedures and techniques. Moreover, we select pyrene as the helical core because pyrene molecule has excellent fluorescence 
features, ${ }^{16}$ that make pyrene and pyrene derivatives are the commonly used fluorescence probes/sensors. ${ }^{17}$ Our final goal is to develop a new class of pyrene-based polycyclic aromatic hydrocarbons (PAHs) with unique optoelectronic properties for 5 applications in optoelectronic devices.

Despite various approaches that are now available, there is no efficient method to construct phenanthrene annulated pyrene helicenes at the 4-, 5-, 9-, and 10-positions. On the other hand, it is well known that electrophilic substitutions of pyrene only 10 occur at 1-, 3-, 6-, and 8-positions but not the other positions (2, $4,5,7,9$, and 10), therefore, pyrene substituted at the latter positions must be prepared in ways other than by the direct electrophilic substitution of pyrene itself. ${ }^{18}$ For example, Moyle and co-worker ${ }^{19}$ have prepared the 4,9-diethylpyrene in a low

15 total yield from ethyl benzene by 14 steps using Friedel-Crafts intramolecular acylation to construct a pyrene ring. Thus, there is substantial interest to investigate the selective introduction of substituents at 4-, 5-, 9-, and 10-positions in the pyrene ring. Along this line, we report here the synthesis, crystal structures 20 and photophysical properties of two types of pyrene-cored bluelight-emitting [4]helicenes (7 and 9) by our previously reported intramolecular photocyclization, ${ }^{14}$ starting from 2,7 -di-tert-butyl4,9-bis(phenylethenyl)pyrenes (6) and 2,7-di-tert-butyl-4,10bis(phenylethenyl)pyrene (8), respectively (Scheme 1, 2 and 3).

\section{${ }_{25}$ Results and discussion}

\section{Synthesis and characterization}

According to our previously report, we readily obtained the intermediates, 2,7-di-tert-butylpyrene-4-carbaldehyde 2, 2,7-ditert-butylpyrene-4,9-biscarbaldehyde 3 and 2,7-di-tert-butylpyre30 ne-4,10-biscarbaldehyde 4 in high yields (Scheme 1). ${ }^{20}$ In the present work, we used the difomylated products $\mathbf{3}$ and $\mathbf{4}$ as the starting materials for the preparation of the pyrene-cored bluelight emitting [4]helicenes.

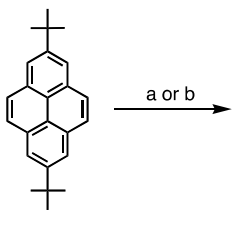

1

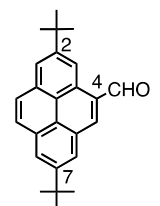

2

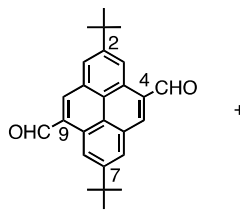

3

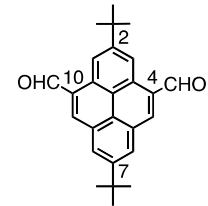

4
Scheme 1 Formylation of 2,7-di-tert-butylpyrene (1). Reagents and 35 conditions: (a) $\mathrm{Cl}_{2} \mathrm{CHOMe}, \mathrm{TiCl}_{4}, \mathrm{CH}_{2} \mathrm{Cl}_{2}, \mathrm{rt}, 12$ h. (b) $\mathrm{Cl}_{2} \mathrm{CHOMe}, \mathrm{AlCl}_{3}$, $\mathrm{CH}_{2} \mathrm{Cl}_{2}, \mathrm{rt}, 12 \mathrm{~h}$

We carried out Wittig reaction of the 4,9- and 4,10difomylated products $\mathbf{3}$ and $\mathbf{4}$ with various arylmethylphosphonium ylides, followed by the intramolecular photocyclization, and ${ }_{40}$ succeeded in preparing the corresponding [4]helicenes $\mathbf{7}$ and $\mathbf{9}$ in good yields (Scheme 2 and 3).
We fully determined the chemical structures and purities of these new pyrene-cored [4] helicenes 7 and 9 by their ${ }^{1} \mathrm{H} /{ }^{13} \mathrm{C}$ NMR spectra, mass spectroscopy and elemental analysis. All ${ }_{45}$ results were well concistent with the proposed structures (see ESI $\dagger$ ). All compounds are very soluble in common organic solvents, such as hexane, $\mathrm{CH}_{2} \mathrm{Cl}_{2}, \mathrm{CHCl}_{3}$, and toluene. Thermal properties of $\mathbf{7 a}-\mathbf{c}$ and $\mathbf{9}$ were investigated by thermogravimetric

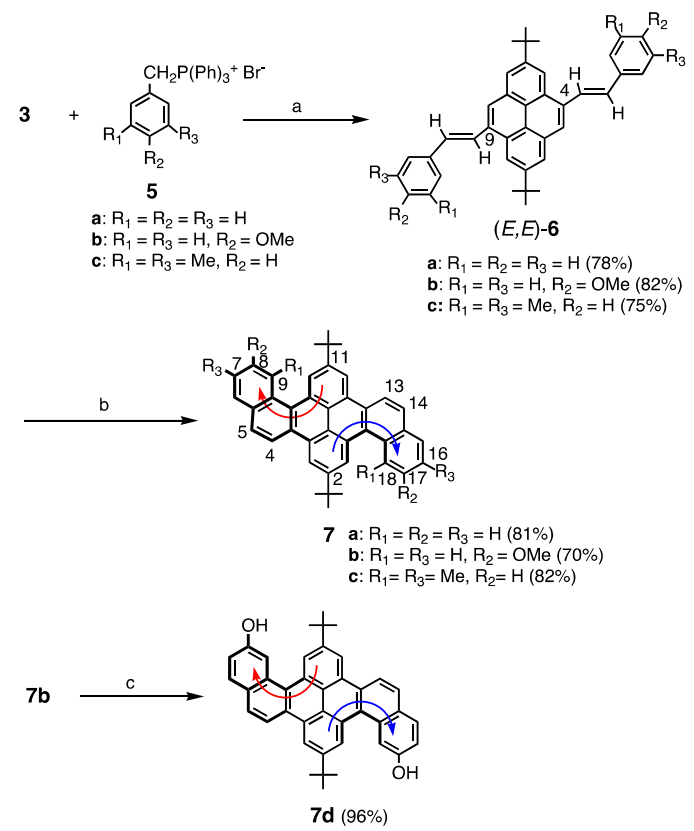

50 Scheme 2 Synthesis of 2,11-di-tert-butyltetrabenzo[ $a, f g, l, o p]$ tetracenes 7a-d. Reagents and conditions: (a) n-BuLi, THF, rt, 6 h. (b) $I_{2}$, propylene oxide, benzene, rt, 12 h. (c) $\mathrm{BBr}_{3}, \mathrm{CH}_{2} \mathrm{Cl}_{2}$, rt, 6 h.

analysis (TGA) and differential scanning calorimetry (DSC) measurements. The decomposition temperatures $\left(T_{\mathrm{d}}\right)$ of the 55 pyrenes $\mathbf{7 a}-\mathbf{c}$ and $\mathbf{9}$ were in the range of $327-395{ }^{\circ} \mathrm{C}$ corresponding to a $5 \%$ weight loss, and the melting points of $7 \mathbf{a}-\mathbf{c}$ and 9 were in the range of $244-261{ }^{\circ} \mathrm{C}$. The key thermal data of the [4] helicenes $\mathbf{7 a - c}$ and $\mathbf{9}$ are summerized in Table 2.
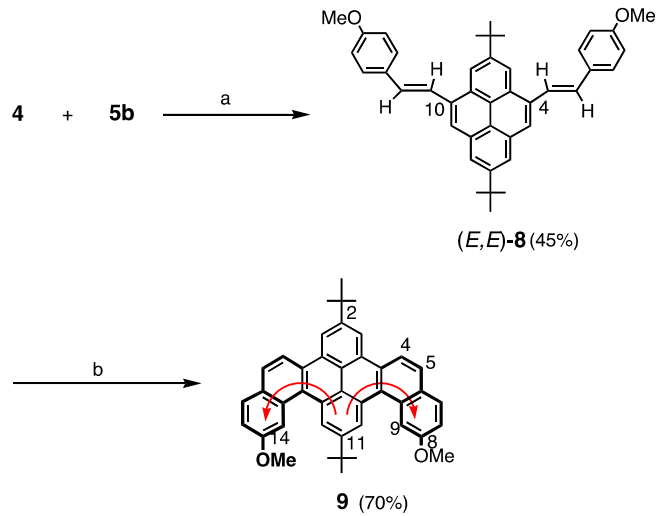

Scheme 3 Synthesis of 2,11-di-tert-butyl-8,14-dimethoxytetrabenzo$[a, f g, l, o p]$ tetracene 9. Reagents and conditions: (a) n-BuLi, THF, rt, 6 h. (b) $\mathrm{I}_{2}$, propylene oxide, benzene, rt. $12 \mathrm{~h}$. 


\section{X-Ray molecular structures and crystal packing}

In order to investigate the nature of the molecular structures of the newly developed pyrene-cored [4] helicenes in the solid state, we obtained suitable crystals of $\mathbf{7 b}, 7 \mathbf{c}$ and $\mathbf{9}$ by using binary solvent systems with vapor diffusion of hexane into dichloromethane solutions. The crystallographic data for the compounds $\mathbf{7 b}, \mathbf{7 c}$ and $\mathbf{9}$ are summarized in Table S1 (see ESI $\dagger$ ). ${ }^{21}$ The helicene $\mathbf{7 b}$ lies on a two-fold axis (Fig. 1). For this structure, where slight structural disorder was observed the 10 accuracy of the molecular geometry is lower, though in general sufficient to draw some conclusions. The molecular geometry of the helical skeleton contains short and long $\mathrm{C}-\mathrm{C}$ bonds. The longer bonds are those mostly affected by the intramolecular torsion (namely, C11-C12, C12-C13, C13-C14, C14-C15), 15 average of $1.43 \AA$. It is noteworthy to mention that in the peripheral rings, the $\mathrm{C} 20-\mathrm{C} 21$ bond length $[1.363(4)(\AA)]$ is significantly shorter than counterpart C13-C14 [1.461(4) $(\AA)]$, showing a more twisted structure of peripheral rings because of the rigid pyrene core. The torsion angles along the inner helical 20 rim of upper limbs C11-C12-C13-C14 and C12-C13-C14-C15 are $18.6(5)^{\circ}$ and $19.9(5)^{\circ}$, respectively, and the torsion angles along the inner helical rim of lower limbs C26-C27-C28-C29, and $\mathrm{C} 27-\mathrm{C} 28-\mathrm{C} 29-\mathrm{C} 30$ are $-18.5(5)^{\circ}$ and $-21.5(5)^{\circ}$, respectively. Nonbonding distances $(\AA)$ were calculated as: C37${ }_{25}$ O1: $5.951 \AA$; C25-C1: $5.397 \AA$; and C26-C3: $2.991 \AA$. These values are also a convenient measure of the helicity. ${ }^{22}$ Similar molecular geometry of the helical skeleton for 7c was also observed with corresponding torsion angles along the inner helical rims of the lower limbs C3- C2-C15-C28, C2-C15-C28${ }_{30} \mathrm{C} 29, \mathrm{C} 10-\mathrm{C} 9-\mathrm{C} 8-\mathrm{C} 20$, and $\mathrm{C} 9-\mathrm{C} 8-\mathrm{C} 20-\mathrm{C} 21$ being 21.8(3), $34.5(3), 19.2(3)$ and $33.2(3)^{\circ}$, respectively. These values show a more twisted conformation due to the bulkier Me group at $\mathrm{C} 21$ and $\mathrm{C} 29$ in 7c, compared with $\mathrm{H}$ at $\mathrm{C} 15$ and C30 in $\mathbf{7 b}$. Similarly, as shown in Fig. 1, the molecular geometry of the helical skeleton
${ }_{35}$ for 9 also contains short and long $\mathrm{C}-\mathrm{C}$ bonds. For example, the longer bonds (namely, C4-C3, C3-C32, C32-C31, C31-C30) also average $1.43 \AA$, which is mostly caused by the intramolecular torsion. In the peripheral rings, the bond lengths of C15-C16 [1.356(5) $(\AA)]$ and C24-C25 [1.348(5) $(\AA)]$ are 40 significantly shorter than counterparts of C8-C9 [1.460(5) $(\AA)]$ and $\mathrm{C} 31-\mathrm{C} 32[1.444(5)(\AA)]$ respectively, showing a more twisted structure of the peripheral rings. For the crystal structural conformation of $\mathbf{9}$, the torsion angles along the inner helical rim of right limb $\mathrm{C} 4-\mathrm{C} 3-\mathrm{C} 32-\mathrm{C} 31$ and $\mathrm{C} 3-\mathrm{C} 32-\mathrm{C} 31-\mathrm{C} 30$ are ${ }_{45} 29.2(5)^{\circ}$ and $-19.4(5)^{\circ}$, respectively, and the torsion angles along the inner helical rim of the left limb C6-C7-C8-C9, and C7-C8C9-C10 are $24.3(5)^{\circ}$ and $19.4(5)^{\circ}$, respectively. Therefore, $7 \mathbf{b}$ shows somewhat of the desired pyrene-cored [4] helicene like configurations, in which the two naphthalene-fused [4]helicene${ }_{50}$ like structures linked in the pyrene ring point away from each other (Fig. 1); in contrast, in the crystal conformations of 7c and 9, the two naphthalene-fused [4]helicene arranged in the pyrene ring are located to the same side to form the other type of pyrenecored [4]helicene. The result obtained in the crystal of 9 is 55 probably due to the strong repulsion between the two terminal methoxy groups and the bulky tert-butyl group. Thus, the structural configuration with lower intramolecular tension is established. Moreover, the different crystal structural conformations in $\mathbf{7 b}-\mathbf{c}$ and $\mathbf{9}$ should significantly affect the ${ }_{60}$ photophysical properties of these newly developed pyrene-cored [4]helicenes in both solution and in the solid state. Previously, the crystal packing of pyrene molecules has been fully studied. A card-packed structure was observed and the molecules exhibits inter planar separation of $c a$. $3.5 \AA$ with strong $\pi$ - $\pi$ stacking by ${ }_{65}$ the involvements of 14 carbons in $\pi-\pi$ interactions. ${ }^{23}$ As shown in Fig. 2 and Fig. S20 (see ESI $\dagger$ ), the present helicenes 7b, 7c and 9 are packed in herringbone pattern. However the overall arrangement of the molecules in the crystal lattice shows pattern

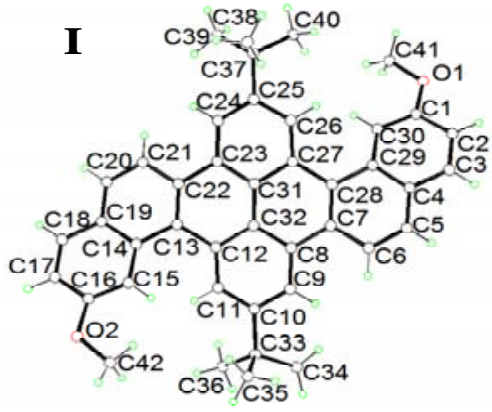

7b

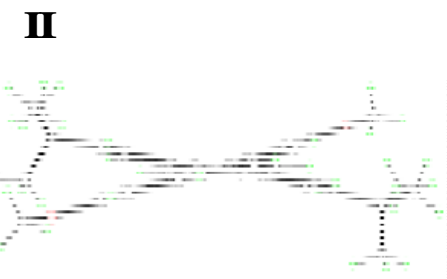

$7 b$

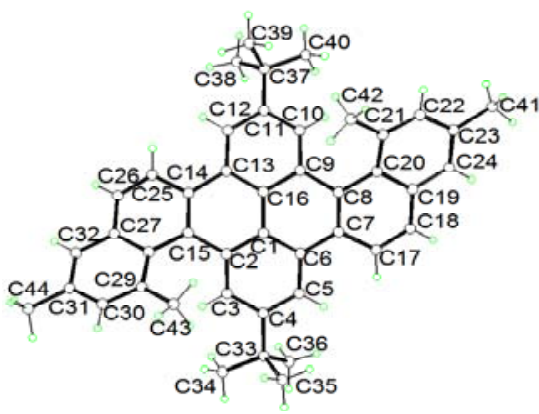

7c

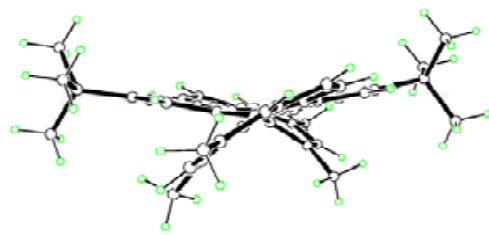

7c

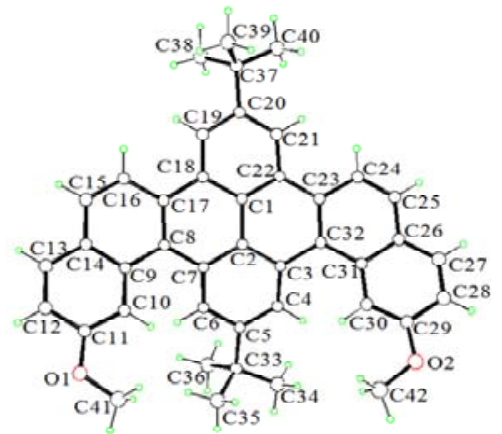

9

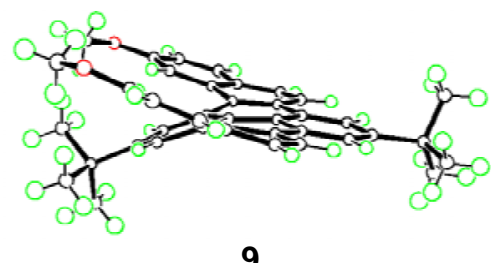

Fig. 1 Molecular structures and conformations for the [4]helicenes 7b, 7c and 9: (I) top views for 7b, 7c and 9, respectively; (II) side views for 7b, 7c and $\mathbf{9}$, respectively. 
I

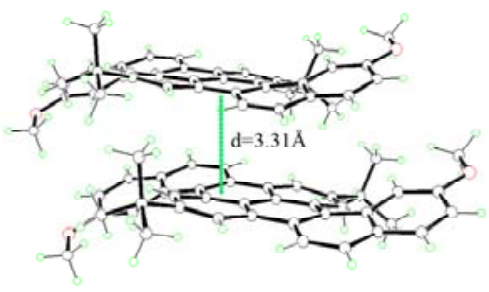

$7 \mathrm{~b}$

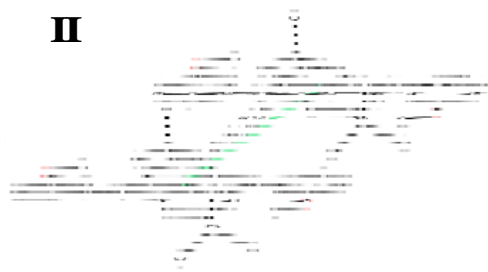

$7 b$

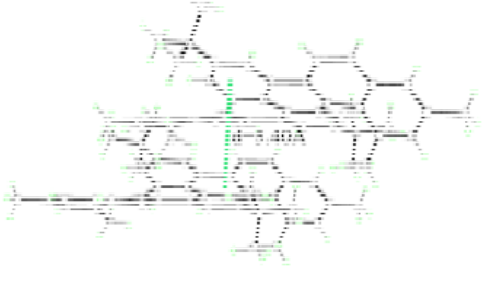

7c

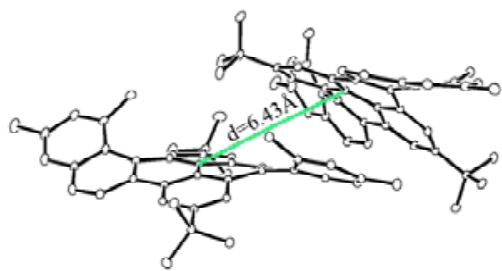

7c

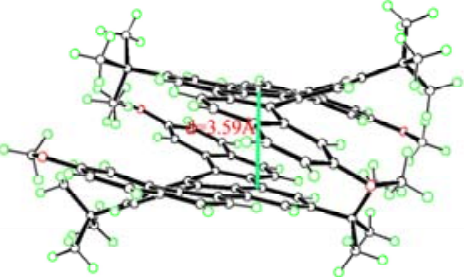

9

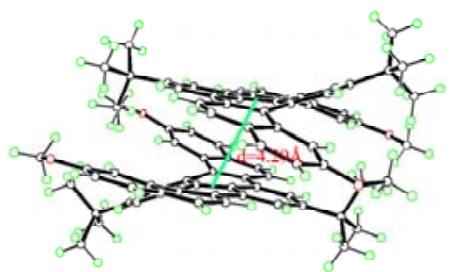

9

Fig. 2 Packing distances and conformations for the [4]helicenes $\mathbf{7 b}, \mathbf{7 c}$ and $\mathbf{9}$ : (I) side views for $\mathbf{7 b}$, 7c and $\mathbf{9}$ between two helicened moieties, respectively; (II) side views for $\mathbf{7 b}, \mathbf{7} \mathbf{c}$ and $\mathbf{9}$ between two pyrene moieties, respectively.

of the ladder-like arrays. Interestingly, the intermolecular distances between the pyrenyl planes of two adjacent molecules in $7 \mathbf{b}, 7 \mathbf{c}$ and 9 are $c a$. $6.22 \AA, 6.43 \AA$ and $4.29 \AA$, respectively, which are not especially short at ca. 3.50-3.70 $\AA,{ }^{24}$ implying the 5 two bulky tert-butyl groups attached in the pyrene rings at 2- and 11-positions played a key role in suppressing the face-to-face $\pi-\pi$ stacking in the solid state. ${ }^{25}$ These longer inter planar distance, which are due to the presence of the bulky tert-butyl groups, could also explain their greater solubility. Interestingly, the ${ }_{10}$ parallel pseudo-stacking between the pyrenyl and sideways aromatic rings were observed in the crystal packing of $\mathbf{7 b}, \mathbf{7} \mathbf{c}$ and $\mathbf{9}$, respectively. In crystal packing of the helicenes $\mathbf{7 b}, \mathbf{7 c}$ and $\mathbf{9}$, the pyrenyl and lateral rings of adjacent molecules lies on planes at the average distance of short contact $c a$. $3.31 \AA$ for $7 \mathbf{b}, 5.40 \AA$

15 for $7 c$ and $3.59 \AA$ for $\mathbf{9}$, respectively, which is suggestive of partial but remarkable intermolecular interaction leading to the strong herring-bone array of molecules in crystal lattices (Fig. 2). Moreover, a comparison of the characteristic ${ }^{1} \mathrm{H}$ NMR spectra of 7 and 9 further suggested that the [4]helicene 9 was synthesized 20 in the conformation in which both naphthalene-fused helical rotates are arranged in the same side sense (Fig. 1). On the other hand, further investigations on: i) The effects of introduced methyl groups in the fjord regions of the helical molecule 7c; and ii) The studies on both the possibility of Van der Waals 25 interactions and patterns of crystal packing for the compound 7d via single-crystal X-ray crystallography analysis are underway in our laboratory.

\section{Photophysical and electrochemical properties}

Firstly, we measured the UV/vis absorption and fluorescence 30 spectra of both the newly developed [4]helicenes (7a-c and 9) and the pre-cyclization products, 4,9- and 4,10-bis(phenylethenyl)pyrenes (6 and 8) in dilute dichloromethane solution at room temperature, and the results are presented in Table 1, together with those of the 2,7-di-tert-butylpyrene (1). ${ }^{14}$ The
35 comparative UV/vis absorption spectra of the [4]helicenes (7a-c and 9) and the 4,9- and 4,10-bis(phenylethenyl)pyrenes (6 and 8) are shown in Fig. 3 and Fig. 4, respectively. For the 2,7-di-tertbutylpyrene $\mathbf{1}$, the absorption spectra is almost identical compared with that of the parent pyrene ${ }^{24}$ with three well40 resolved, sharp absorption band observed in the region 300-350 $\mathrm{nm}$. The slight bathochromic shift is ascribed to the increased electron density on the pyrene ring arising from the electrondonating nature of the tert-butyl groups at the 2- and 7positions. ${ }^{20}$ However, for the UV/Vis absorption spectra of the ${ }_{45}$ pre-cyclization products, $\mathbf{6}$ and $\mathbf{8}$, all spectra are broad, less well resolved and the longest wavelength hyperchromic absorption maxima occur at $370 \mathrm{~nm}$ for $\mathbf{6 a}, 374 \mathrm{~nm}$ for $\mathbf{6 b}, 372 \mathrm{~nm}$ for $\mathbf{6 c}$, and $350 \mathrm{~nm}$ for $\mathbf{8}$, respectively (Table 1), which are bathochromically red-shifted by $c a$. 11-35 nm compared with 50 that of $\mathbf{1}$, arising from the two phenylene-vinylene chromophores that introduced in the pyrene ring at 4,9- or 4,10-positions (Fig. $3)$. Interestingly, among the UV/vis absorption spectra of the 4,9isomer $\mathbf{6}$ and the 4,10-isomer 8, the latter shows less bathochromically red shift (ca. $11 \mathrm{~nm}$ ) (Fig. 4). A reasonable 55 explanation for these different shifts is that there are quite different conjugation lengths and conjugation pathways in the two molecular systems. In addition, among the compounds $\mathbf{6}$, the methoxy-substituted phenylethenylpyrene $\mathbf{6 b}$ displays the largest bathochromic shift of the absorption band, which can be ${ }_{60}$ attributed to the strongest electron-donating nature of the methoxy group compared to the $-\mathrm{H}(\mathbf{6 a})$ or $-1,3$-dimethyl (6c) substituents. The result further demonstrates that the effects of substitution are observed in the UV/vis absorption spectra of $\mathbf{6}$, for example, with the increase in the electron-donating nature of 65 the substituents, the spectra was found to be more bathochromically red shifted, i.e. $\mathbf{6 a}<\mathbf{6 c}<\mathbf{6 b}$. On the other hand, for the UV/vis absorption spectra of the [4] helicenes $7 \mathbf{a}-\mathbf{c}$ and 9, the profiles of these spectra are almost identical and the absorption bands were observed in the range of 280-410 nm (Fig. 
3 and Fig. 4), ${ }^{14,25}$ which showed a large number transition bands typically for the PAHs. ${ }^{26}$ However, the profiles of the UV/Vis absorption spectra of the cyclized products $\mathbf{7 a - c}$ and $\mathbf{9}$ are quite different with those of the pre-cyclization products $\mathbf{6}$ and $\mathbf{8}$, 5 which could be ascribed to the expanded conjugation of the $\pi$ electron systems of PAHs after the cyclization reaction. Therefore, the pronounced decrease (hypochromic absorption) of absorption bands in the ranges of 340-410 nm after cyclization are attributed to the absence of the phenylethenyl units, the 10 decrease of aromaticity and the increase of distortions form the plane. Furthermore, the departure from co-planarity with the aromatic ring is also pronounced with methoxy substituents groups, which is ascribed by the absorption bands at 406 and 404 $\mathrm{nm}$ for $\mathbf{7 b}$ and $\mathbf{9}$, respectively. Thus, the absence of the bands 15 over $400 \mathrm{~nm}$ in the UV/vis absorption spectra of 7c confirms the increased non-planarity of the aromatic ring to avoid the steric crowing by the overlapping at the $\mathrm{C}_{1,10}$ protons in the pyrene ring and the methyl groups at $\mathrm{C}_{9,18}$ leading to increased strain in these system. $^{14,25}$

20

Table 1 Optical UV-Vis and emission spectroscopic data for $\mathbf{6 a - c}, \mathbf{7 a - c}$ 8 and 9 in $\mathrm{CH}_{2} \mathrm{Cl}_{2}\left(\sim 10^{-5}-\sim 10^{-6} \mathrm{M}\right)$ at $25^{\circ} \mathrm{C}$, compared with that of 2,7di-tert-butylpyrene $\mathbf{1}{ }^{a}$

\begin{tabular}{lllll}
\hline Compd & $\begin{array}{l}\text { Absorption }^{b} \\
\lambda_{\text {abs }}[\mathrm{nm}]\end{array}$ & $\begin{array}{l}\text { Fluorescence }^{c} \\
\lambda_{\max }[\mathrm{nm}]\left(\lambda_{\mathrm{ex}}\right)^{d}\end{array}$ & $\begin{array}{l}\text { Stokes-shift } \\
{[\mathrm{nm}]}\end{array}$ & $\Phi_{\mathrm{f}}{ }^{e}$ \\
\hline $\mathbf{1}$ & 339 & $378(252)$ & 39 & 0.12 \\
$\mathbf{6 a}$ & 370 & $480(304)$ & 110 & 0.77 \\
$\mathbf{6 b}$ & 374 & $484(308)$ & 110 & 0.84 \\
$\mathbf{6 c}$ & 372 & $481(306)$ & 109 & 0.85 \\
$\mathbf{7 a}$ & 368 & $401(315)$ & 33 & 0.13 \\
$\mathbf{7 b}$ & 382 & $406(316)$ & 24 & 0.22 \\
$\mathbf{7 c}$ & 378 & $422(320)$ & 54 & 0.15 \\
$\mathbf{8}$ & 350 & $444(345)$ & 94 & 0.60 \\
$\mathbf{9}$ & 380 & $408(321)$ & 28 & 0.23
\end{tabular}

${ }^{a}$ All measurements were performed under degassed condition. ${ }^{b} \sim \times 10^{-5}$ $\mathrm{M}$ in $\mathrm{CH}_{2} \mathrm{Cl}_{2}, \lambda_{\text {abs }}$ is the absorption band appearing at the longest wavelength. ${ }^{c} \sim \times 10^{-6} \mathrm{M}$ in $\mathrm{CH}_{2} \mathrm{Cl}_{2}, \lambda_{\text {ex }}$ is the fluorescence band appearing at the shortest wavelength. ${ }^{d}$ Wavelength of excitation. ${ }^{e}$ Absolute quantum yield in $\mathrm{CH}_{2} \mathrm{Cl}_{2}$ at $\sim 10^{-6}$

25 Upon excitation, a dilute solution $\left(\sim 10^{-6} \mathrm{M}\right)$ of the precyclization compounds $\mathbf{6}$ and $\mathbf{8}$ along with the pyrenes $\mathbf{1}$ in dichloromethane at room temperature shows broad band blue emission, respectively (Fig. 5 and Fig. 6). Compared with the higher energy emission band of 2,7-tert-butylpyrene $1{ }^{20}$ the

30 lower energy emission bands of $\mathbf{6 a}, \mathbf{6} \mathbf{b}$ and $\mathbf{6 c}$ were found to be red shifted to 480,484 and $481 \mathrm{~nm}$, respectively, arising from their expanded conjugation of $\pi$-electron system of the two phenylethenyl units. All emission bands of $\mathbf{6}$ are broad, but almost identical, only one emission band was observed in the 35 visible sky-blue region, a strong indication of the emission from the lowest excited state, while the fluorescence stokes's shift increases in the order of $\mathbf{6 b}=\mathbf{6} \mathbf{a}>\mathbf{6 c}$. Similarly, compared with the lower emission band of $\mathbf{1}$, the lower energy emission band of 8 was also found to be shift to the pure-blue region of $444 \mathrm{~nm}$. ${ }_{40}$ On the other hand, as comparisons, the maximum emission spectra of the [4] helicenes $\mathbf{7 a - c}$ and $\mathbf{9}$ in dichloromethane are also shown in Fig. 5 and Fig. 6. Compared with the lower energy band of the compound $\mathbf{1}$, the bands of 4,9- and 4,10-isomer cyclized [4]helicenes $\mathbf{7 a - c}$ and $\mathbf{9}$ were found to be largely 45 hypochromically red-shifted at $401 \mathrm{~nm}$ for $7 \mathbf{a}, 406 \mathrm{~nm}$ for $\mathbf{7 b}$, $422 \mathrm{~nm}$ for 7c and $408 \mathrm{~nm}$ for 9 with a small shoulder in each spectrum, respectively. All fluorescence emission bands of $\mathbf{7 a - c}$ and $\mathbf{9}$ are sharper than the corresponding pre-cyclization compounds $\mathbf{6}$ and $\mathbf{8}$, and were observed in the deep-blue visible ${ }_{50}$ regions $(400-450 \mathrm{~nm})$. It should be noted here that the profile of the emission band of $7 \mathbf{c}$ is quite different with those of $7 \mathbf{a}, 7 \mathbf{b}$ and 9. A good explanation is that the former (7c) has a more larger twisted helical conformation compared to the latter (7a, $\mathbf{7 b}$ and $\mathbf{9})$ owing to the different substituents, which is also well manner 55 with their single-crystal X-ray analysis. Furthermore, compared to those of the 4,9-isomer cyclized [4] helicenes $7 \mathbf{a}-\mathbf{c}$, the 4,10isomer cyclized [4] helicenes 9 shows a hypsochromically blueshift, which is probably due to the different annulations and the helical conformations.

60 Secondly, we measured the UV/Vis absorption spectra and emission spectra of $\mathbf{7 a - c}$ and $\mathbf{9}$ in thin neat films, and the

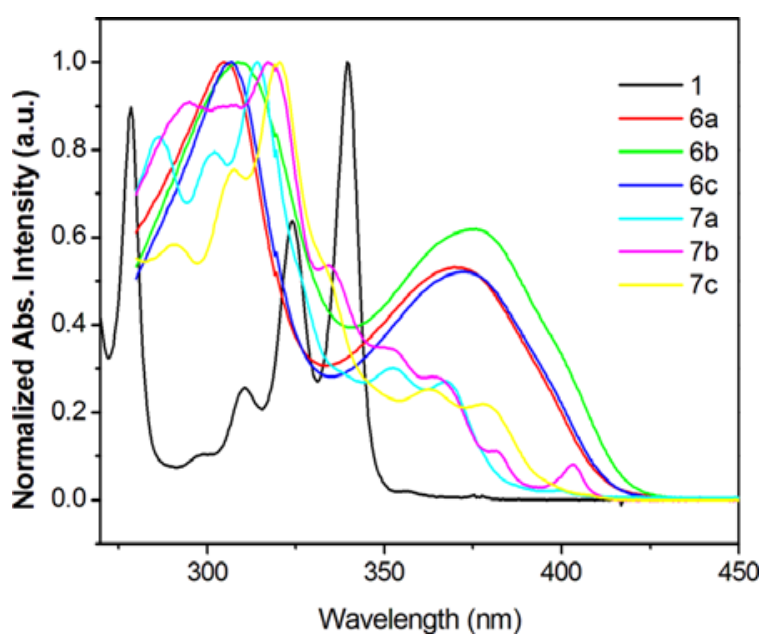

Fig. 3 Normalised UV/Vis absorption spectra of $\mathbf{6}$ and $\mathbf{7 a - c}$ recorded in ${ }_{65} \mathrm{CH}_{2} \mathrm{Cl}_{2}$ at $\sim 10^{-5} \mathrm{M}$ concentration at $25{ }^{\circ} \mathrm{C}$, compared with that of 2,7-ditert-butylpyrene 1 .

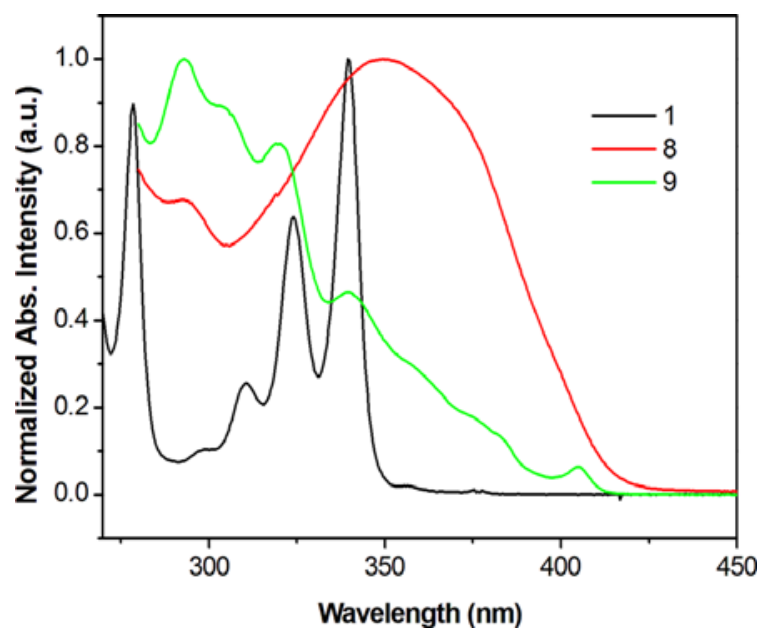

Fig. 4 Normalised UV/Vis absorption spectra of 8 and $\mathbf{9}$ recorded in $70 \mathrm{CH}_{2} \mathrm{Cl}_{2}$ at $\sim 10^{-5} \mathrm{M}$ concentration at $25{ }^{\circ} \mathrm{C}$, compared with that of 2,7 -ditert-butylpyrene $\mathbf{1}$. 
Table 2 Photophysical and electrochemical properties of the [4]helicenes $7 \mathbf{a}-\mathbf{c}$ and $\mathbf{9}$

\begin{tabular}{|c|c|c|c|c|c|c|c|c|c|c|}
\hline $\begin{array}{l}\text { [4]helicenes } \\
\text { molecules }\end{array}$ & $\begin{array}{l}\lambda_{\max \text { abs }}{ }^{a} \\
(\mathrm{~nm})\end{array}$ & $\begin{array}{l}\lambda_{\max \mathrm{em}^{a}}(\mathrm{~nm} \\
\text { monomer }\end{array}$ & excimer & $\begin{array}{l}\lambda_{\operatorname{max~em}}{ }^{b} \\
(\mathrm{~nm})\end{array}$ & $\begin{array}{l}\Phi_{\mathrm{f}} \text { thin neat } \\
\text { films/doped films }\end{array}$ & $\begin{array}{l}E_{\mathrm{g}}{ }^{c} \\
(\mathrm{eV})\end{array}$ & $\begin{array}{c}\mathrm{HOMO}^{d} \\
(\mathrm{eV})\end{array}$ & $\begin{array}{l}\mathrm{LUMO}^{e} \\
\quad(\mathrm{eV})\end{array}$ & $\begin{array}{l}T_{\mathrm{m}}{ }^{f} \\
\left({ }^{\circ} \mathrm{C}\right)\end{array}$ & $\begin{array}{l}T_{\mathrm{d}}{ }^{g} \\
\left({ }^{\circ} \mathrm{C}\right)\end{array}$ \\
\hline $7 a$ & 388 & 412 & 484 & 401 & $0.06 / 0.12$ & 3.06 & -5.89 & -2.83 & 244 & 359 \\
\hline $7 \mathbf{b}$ & 385 & 413 & 500 & 406 & $0.19 / 0.21$ & 2.99 & -5.85 & -2.86 & 249 & 395 \\
\hline 7c & 393 & 427 & 481 & 421 & $0.10 / 0.15$ & 3.04 & -5.78 & -2.74 & 261 & 327 \\
\hline 9 & 384 & 412 & 508 & 407 & $0.18 / 0.22$ & 3.01 & -5.82 & -2.81 & 256 & 370 \\
\hline
\end{tabular}

${ }^{a}$ Measured in thin neat films. ${ }^{b}$ Measured $1 \mathrm{wt} \%$ doped polymethylmethacrylate (PMMA) films, respectively. ${ }^{c}$ Optical band gap estimated from onset point (onset) of absorption band of thin film: $E_{\mathrm{opt}}=1240 / \lambda_{\text {onset }}{ }^{d}$ Calculated from the oxidation potentials. ${ }^{e}$ Calculated from the HOMO energy levels and $E_{\mathrm{g}} .{ }^{f}$ Melting temperature $\left(T_{\mathrm{m}}\right)$ obtained from differential scanning calorimetry (DSC) measurement. ${ }^{g}$ Decomposition temperature $\left(T_{\mathrm{d}}\right)$ obtained from thermogravimetric analysis (TGA).

spectroscopic data are summarized in Table 2. The normalized $\mathrm{UV} / \mathrm{V}$ is absorption spectra and emission spectra of $\mathbf{7 a - c}$ and $\mathbf{9}$ are shown in Fig. 7 and Fig. S21 (See ESI $\dagger$ ), respectively. As shown in Fig. 7, compared to the corresponding spectra in 5 solution, for $\mathbf{7 b}$ and $\mathbf{9}$, a small bathochromic shift $(\sim 3 \mathrm{~nm})$ was observed in each molecule, which indicates that these two

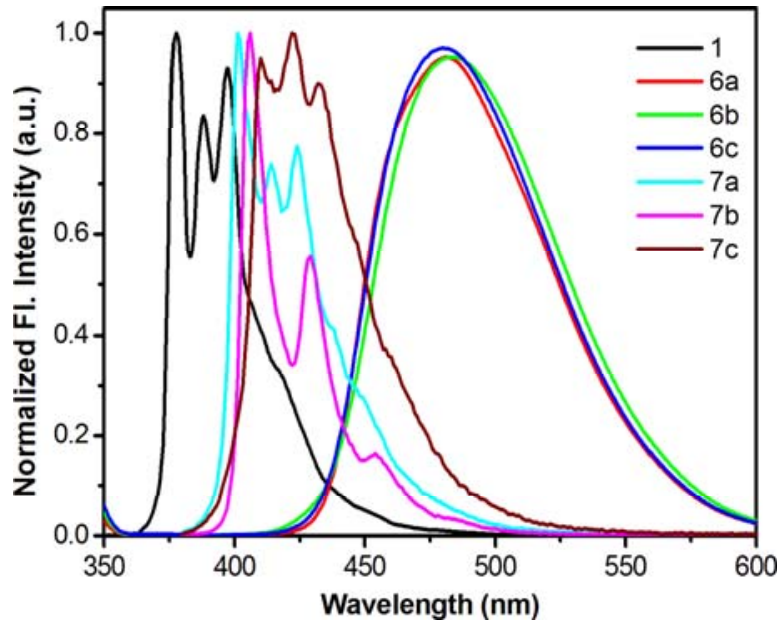

Fig. 5 Normalised emission spectra of $\mathbf{6}$ and $\mathbf{7 a}-\mathbf{c}$ recorded in $\mathrm{CH}_{2} \mathrm{Cl}_{2}$ at $10 \sim 10^{-6} \mathrm{M}$ concentration at $25{ }^{\circ} \mathrm{C}$, compared with that of 2,7-di-tertbutylpyrene 1 .

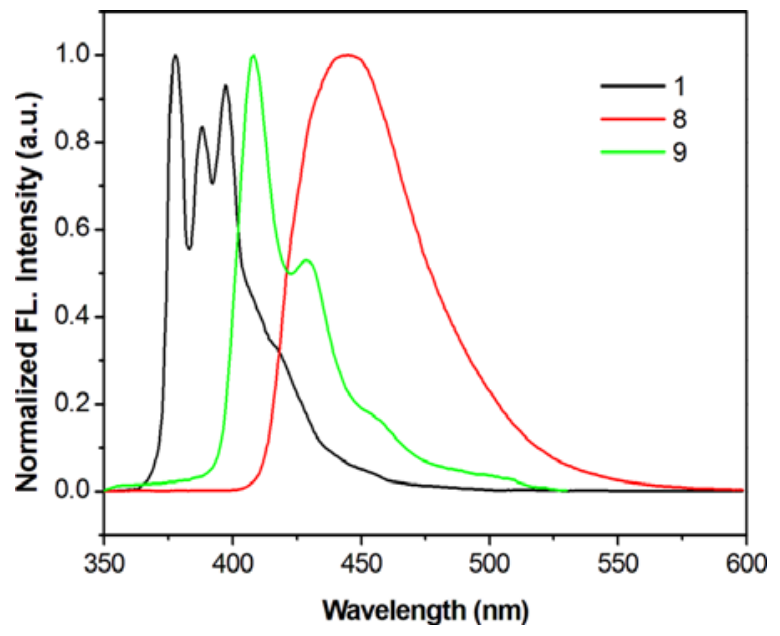

Fig. 6 Normalised emission spectra of 8 and 9 recorded in $\mathrm{CH}_{2} \mathrm{Cl}_{2}$ at $\sim 10^{-6}$ $15 \mathrm{M}$ concentration at $25^{\circ} \mathrm{C}$, compared with that of 2,7-di-tert-butylpyrene 1 . compounds have similar conformations in both states ${ }^{27}$ however, for 7a and 7c, a obvious vibronic absorption band was observed with larger bathochromic shift $(\sim 15-20 \mathrm{~nm})$ in the rang of $350-400 \mathrm{~nm}$ in each compound. These hypsochromic shifts going 20 from solution to films are probably due to both the presence of strong intermolecular $\pi-\pi$ aggregations and different molecular conformations. An interesting fluorescence phenomenon was found in the emission spectra of $\mathbf{7 a - c}$ and $\mathbf{9}$ in Fig. S21 (See ESI $\dagger$ ). All emission spectra show two regions of interest. For 7a, 25 there is a set of partially resolved bands across the $\lambda=400-460$ region but the spectra are dominated by a feature-less band centred at $484 \mathrm{~nm}$, while for $\mathbf{7 b}, \mathbf{7 c}$ and $\mathbf{9}$, there are two sets of both a resolved maximum band at $413 \mathrm{~nm}$ for $7 \mathbf{b}, 427 \mathrm{~nm}$ for $7 \mathbf{c}$ and $412 \mathrm{~nm}$ for $\mathbf{9}$, and a well-resolved band centred at $500 \mathrm{~nm}$ for ${ }_{30} \mathbf{7 b}, 481 \mathrm{~nm}$ for $7 \mathbf{c}$ and $508 \mathrm{~nm}$ for 9, respectively. Based on previous work on pyrene derivatives, ${ }^{28}$ the higher-energy bands can be attributed to monomer emission, whereas the lower-energy bands can be assigned to excimer emissions. The results are also well consistent with the single-crystal X-ray analysis and the

${ }_{35} \mathrm{UV} / \mathrm{Vis}$ absorption spectra. We further examined the fluorescence emission spectra of $\mathbf{7 a - c}$ and $\mathbf{9}$ in thin films doped into polymethylmethacrylate (PMMA) at the $1 \mathrm{wt} \%$ level. ${ }^{29} \mathrm{We}$ observed a deep-blue emission with a maximum peak at $401 \mathrm{~nm}$ for $7 \mathbf{a}, 406 \mathrm{~nm}$ for $\mathbf{7 b}, 421 \mathrm{~nm}$ for 7c, and $407 \mathrm{~nm}$ for 9 (Fig. 8), 40 respectively, which is almost identical to the corresponding emission in solution, indicating the formation of strong intermolecular $\pi-\pi$ aggregations of pyrene units can be suppressed in the doped films. The results suggests these newly developed [4]helicenes $\mathbf{7 a - c}$ and $\mathbf{9}$ might be promising 45 candidates in the fabrication of host-guest-based OLEDs. ${ }^{30}$ All data are also presented in Table 2 .

The fluorescence quantum yields of $\mathbf{7 a - c}$ and $\mathbf{9}$ recorded in dilute dichloromethane solution $\left(\sim 10^{-6} \mathrm{M}\right)$ and thin films at room temperature are also summarized in Table 1 and 2, respectively,

50 together with those of $\mathbf{1 , 6}$ and $\mathbf{8}$. We found the $\Phi_{\mathrm{f}}$ values of the pre-cyclization products $\mathbf{6}$ and $\mathbf{8}$ were quite high ranging from 0.77 to 0.85 , while the $\Phi_{\mathrm{f}}$ values of the cyclized [4] helicenes $7 \mathbf{a}-\mathbf{c}$ and $\mathbf{9}$ were moderate ranging from 0.06 to 0.23 . A possible explanation for this is: For these [4]helicenes, 7a-c and 9, low ${ }_{55}$ quantum yields were obtained in solution and the thin neat films, which indicates that excitons were not confined to the whole backbone of these molecules due to its non-planar molecular structures. Some energy loss might happen during the exciton migrations, ${ }^{31}$ thereby resulting in low quantum yields. In contrast, ${ }_{60}$ for the pre-cyclization compounds, $\mathbf{6}$ and $\mathbf{8}$, high fluorescence 
quantum yields were found in solution, indicating the excitons were completely confined to the whole backbone of $\mathbf{6}$ and $\mathbf{8}$, arising from the significantly expanded $\pi$-delocalization between the rigid phenylethenyl groups and the central pyrene core, 5 thereby giving higher quantum yields.

Finally, we investigated the electrochemical characteristics of the pyrenes $7 \mathbf{a}-\mathbf{c}$ and $\mathbf{9}$ by using cyclic voltammetry $(\mathrm{CV})$. The pyrenes were scanned positively, separately, in $0.10 \mathrm{M}$ tetrabutylammonium perchlorate $\left(\mathrm{Bu}_{4} \mathrm{NClO}_{4}\right)$ in anhydrous 10 dichloromethane with a scan rate of $50 \mathrm{mV} \mathrm{s}^{-1}$ at room temperature. We find that the oxidation of the pyrenes was quasireversible or reversible processes (Fig. S22, see ESI $\dagger$ )). The halfwave potentials for oxidation were $1.49,1.45,1.38$, and $1.42 \mathrm{~V}$ $\left(v s \mathrm{Fc} / \mathrm{Fc}^{+}\right)$for $\mathbf{7 a}, \mathbf{7 b}, \mathbf{7 c}$, and $\mathbf{9}$, respectively. From the lowest15 energy absorption edge of the UV-vis absorption spectra in thin

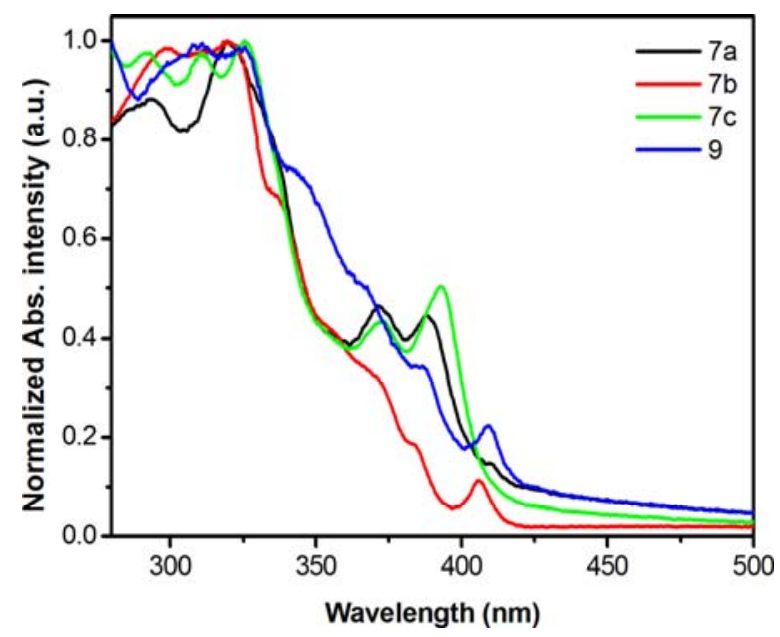

Fig. 7 Normalised UV/Vis absorption spectra of $\mathbf{7 a - c}$ and $\mathbf{9}$ recorded in 20 thin neat films.

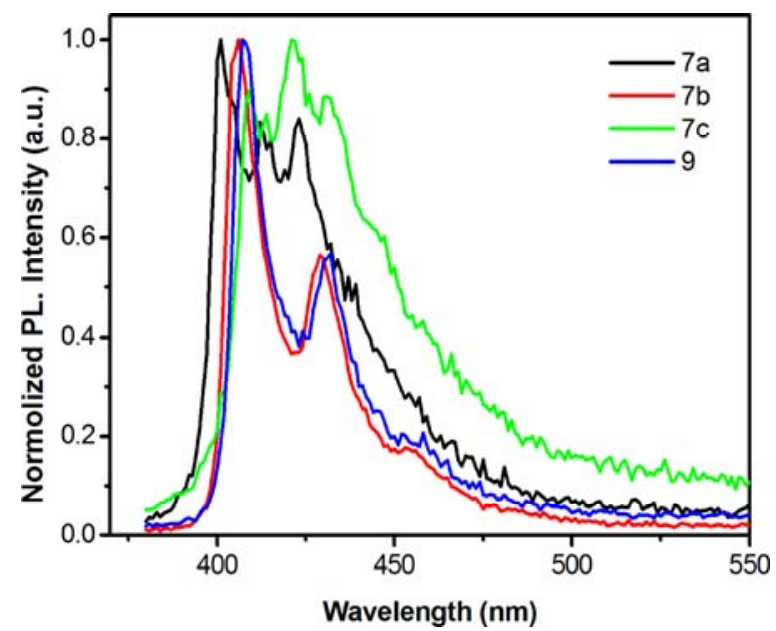

Fig. 8 Emission spectra of $\mathbf{7 a - c}$ and $\mathbf{9}$ in thin films doped into PMMA at the 1 wt. $\%$ level.

25 neat films, the band gaps $\left(E_{\mathrm{g}}\right)$ of the pyrenes were 3.06, 2.99, 3.04, and $3.01 \mathrm{eV}$ for $\mathbf{7 a}, \mathbf{7 b}, \mathbf{7 c}$, and $\mathbf{9}$, respectively. Thus, according to the equation, ${ }^{32} \mathrm{IP}=-\left(\left[E_{\text {onset }}\right]^{\text {ox }}+4.4\right) \mathrm{eV}$, where
$\left[\mathrm{E}_{\text {onset }}\right]^{\mathrm{ox}}$ is the half-wave potentials for the oxidation of the pyrenes versus the reference electrode. The lowest unoccupied 30 molecular orbital (LUMO) and highest occupied molecular orbital (HOMO) of the pyrenes were LUMO: $-2.83,-2.86,-2.74$, -2.81 ; HOMO: $-5.89,-5.85,-5.78$, and $-5.82 \mathrm{eV}$ for $7 \mathrm{a}, 7,7 \mathrm{c}$, and $\mathbf{9}$, respectively. It was observed that the $E_{\mathrm{g}}$ values of $\mathbf{7 a}-\mathbf{7 c}$ varied slightly due to the difference of the R-substituents, and 35 indicates that different substituents in these pyrenes can inevitably result in different energy states of the whole molecule. Furthermore, the calculated HOMO values of $\mathbf{7 a - c}$ and $\mathbf{9}$ vary slightly in the range -5.89 to $-5.78 \mathrm{eV}$, indicating that the materials are promising deep-blue emitters for applications in ${ }_{40}$ OLED-like optoelectronic devices. ${ }^{33}$ All data of electrochemical characteristics for the pyrenes $\mathbf{7 a - c}$ and $\mathbf{9}$ are also summarized in Table 2 .

\section{Conclusions}

In conclusion, we have developed two types of new pyrene-cored 45 blue-light emitting [4]helicenes via intramolecular photocyclisation in good yields and fully characterised the special chemical structures. The single-crystal X-ray analysis revealed that the terminal substituents groups (i.e. methoxy and dimethyl) and the two tert-butyl groups played the key roles for 50 constructing the formation of the helical conformations. These longer interplanar distance, which are due to the presence of the sterically bulky tert-butyl groups, could also explain their greater solubility. Furthermore, the results obtained through inspecting the absorption and emission spectra of the phenylethenyl55 functionalised molecules (6 and 8) in solution, and the helical molecules (7a-c and 9) in both solution and the solid state demonstrated that both of them exhibited bright fluorescent emissions from deep-blue to sky-blue visible regions with notable optical features, that make them potential candidates for several 60 important applications in modern electronic and optoelectronic devices, such as blue emitters in OLEDs, or as models for further investigating the development of a new generation of pyrenebased organic materials.

\section{Experimental}

\section{${ }_{65}$ Genenal}

${ }^{1} \mathrm{H}$ and ${ }^{13} \mathrm{C}$ NMR spectra were recorded on JEOL $300(300 \mathrm{MHz}$ and $75 \mathrm{MHz}$ ) spectrometers. Mass spectra were obtained on a Nippon Denshi JMS-HX110A Ultrahigh Performance Mass Spectrometer at $75 \mathrm{eV}$ using a direct-inlet system. Elemental 70 analyses were performed with a Yanaco MT-5 analyser. Thermogravimetric analysis (TGA) was undertaken using a SEIKO EXSTAR 6000 TG/DTA 6200 unit under nitrogen atmosphere at a heating rate of $10{ }^{\circ} \mathrm{C} \mathrm{min}^{-1}$. Differential scanning calorimetry (DSC) was performed using a Perkin-Elmer Diamond 75 DSC Pyris instrument under nitrogen atmosphere at a heating rate of $10{ }^{\circ} \mathrm{C} \mathrm{min}{ }^{-1}$. UV-Vis spectra were measured using a Shimadzu UV-3150 UV-vis-NIR spectrophotometer. Photoluminescence spectra were obtained using a FluroMax-2 (Jobin-Yvon-Spex) luminescence spectrometer. Electrochemical properties of ${ }_{80}$ HOMO and LUMO energy levels were determined by Electrochemical Analyzer. 
Materials. Preparation of 2,7-di-tert-butylpyrene (1) was previously described. ${ }^{18}$

${ }_{5}$ Formylation of 2,7-di-tert-butylpyrene (1) with $\mathrm{Cl}_{2} \mathrm{CHOMe}$ in the presence of $\mathrm{AlCl}_{3}$ : To a stirred solution of $\mathbf{1}(5 \mathrm{~g}, 16.00$ $\mathrm{mmol})$ and dichloromethyl methyl ether $(20 \mathrm{~mL}, 224.00 \mathrm{mmol})$ in $\mathrm{CH}_{2} \mathrm{Cl}_{2}(150 \mathrm{~mL})$ was gradually added a powdered aluminum chloride $(13.3 \mathrm{~g}, 100.00 \mathrm{mmol})$ at $0{ }^{\circ} \mathrm{C}$. This mixture was stirred 10 for $12 \mathrm{~h}$ at room temperature. The reaction mixture was poured into a large amount of ice-water and extracted with $\mathrm{CH}_{2} \mathrm{Cl}_{2}(2 \times$ $300 \mathrm{~mL})$. The organic layer was washed with water $(2 \times 100 \mathrm{~mL})$, dried over $\mathrm{MgSO}_{4}$, and evaporated in vacuo. The residue was washed with a hot mixture of hexane-ethyl acetate $(5: 1)(2 \times 300$

$15 \mathrm{~mL})$ and filtered. The filtrate was concentrated and washed with a hot mixture of hexane-methanol $(10: 1)(100 \mathrm{~mL})$ to afford the pure 2,7-di-tert-butylpyrene-4,9-biscarbaldehyde 3 (3.8 g, 65\%) as a yellow solid. Recrystallization from hexane afforded 2,7-ditert-butylpyrene-4,9-biscarbaldehyde $3(3.3 \mathrm{~g}, 55 \%)$ as pale 20 yellow prisms. M.p. $247{ }^{\circ} \mathrm{C} .{ }^{1} \mathrm{H}$ NMR $\left(300 \mathrm{MHz}, \mathrm{CDCl}_{3}\right): \delta=$ $1.63(\mathrm{~s}, 18 \mathrm{H}, t \mathrm{Bu}), 8.44\left(\mathrm{~d}, 2 \mathrm{H}, J=1.8 \mathrm{~Hz}, \operatorname{Ar}-H_{1,6}\right), 8.60(\mathrm{~s}, 1 \mathrm{H}$, Ar- $\left.H_{5,10}\right), 9.92\left(\mathrm{~d}, 2 \mathrm{H}, J=1.8 \mathrm{~Hz}, \mathrm{Ar}-H_{3,8}\right), 10.52$ (s, 2H, CHO) ppm. MS (EI): $m / z: 370\left[\mathrm{M}^{+}\right] . \mathrm{C}_{26} \mathrm{H}_{26} \mathrm{O}_{2}$ (370.48): calcd. C 84.29, H 7.07; found C 84.27, H 7.08.

25 On the other hand, the filtrate was evaporated to leave the residue which was chromatographed over silica gel (Wako, C$300 ; 200 \mathrm{~g}$ ) with a toluene as eluent afforded a mixture of 2,7-ditert-butylpyrene-4,9-biscarbaldehyde (3) and 2,7-di-tert-butylpyrene-4,10-biscarbaldehyde (4), in which ratio is determined as 3050 : 50 by ${ }^{1} \mathrm{H}$ NMR spectrum. Although several attempted isolations of 2,7-di-tert-butylpyrene-4,10-biscarbaldehyde 3 in pure failed, the compound 4 was easily conformed by its ${ }^{1} \mathrm{H}$ NMR spectra and GC analysis in the mixture, and thus, the crude was directly used to the next Wittig reaction. ${ }^{1} \mathrm{H}$ NMR $(300$ $\left.{ }_{35} \mathrm{MHz}, \mathrm{CDCl}_{3}\right): \delta=1.62(\mathrm{~s}, 9 \mathrm{H}, t \mathrm{Bu}), 1.64(\mathrm{~s}, 9 \mathrm{H}, t \mathrm{Bu}), 8.51(\mathrm{~s}$, $\left.2 \mathrm{H}, \operatorname{Ar}-H_{6,8}\right), 8.57$ (s, $\left.2 \mathrm{H}, \operatorname{Ar}-H_{1,3}\right), 9.82$ (s, $\left.2 \mathrm{H}, \operatorname{Ar}-H_{5,9}\right), 10.56$ (s, $2 \mathrm{H}, \mathrm{CHO}) \mathrm{ppm}$.

Synthesis of (E,E)-2,7-di-tert-butyl-4,9-bis(phenylethenyl)pyr40 ene (E,E)-6a: The Wittig reagent was prepared from triphenylphosphane and benzyl chloride in dry benzene. To a solution of this Wittig reagent $(2.3 \mathrm{~g}, 6.00 \mathrm{mmol})$ in dry THF (15 $\mathrm{mL})$ was slowly added $n$-butyllithium in hexane $(3.5 \mathrm{~mL}, 3.00$ mmol) at $0{ }^{\circ} \mathrm{C}$ under argon. The mixture was stirring for 10 45 minutes and a solution of 2,7-di-tert-butylpyrene-4,9biscarbaldehyde $2(372 \mathrm{mg}, 1.00 \mathrm{mmol})$ in dry THF $(15 \mathrm{~mL})$ was injected into this mixture under same conditions. The mixture was heated to room temperature stirring for $6 \mathrm{~h}$ under argon. The mixture was quenched by large amount of water, extracted with ${ }_{50}$ ethyl acetate $(2 \times 100 \mathrm{~mL})$. The combined extracts were washed with brine and water, dried with $\mathrm{MgSO}_{4}$ and concentrated. The residue was chromatographed over silica gel (Wako C-300, 200 g) with hexane : ethyl acetate $(5: 1)$ as eluents to give lightyellow solids. Recrystallization from hexane only afforded $(E, E)$ ${ }_{55}$ 2,7-di-tert-butyl-4,9-bis(phenylethenyl)pyrene $(E, E)$-6a (404 mg. $78 \%$ ) as light-yellow solids. M.p. $303{ }^{\circ} \mathrm{C} .{ }^{1} \mathrm{H}$ NMR $(300 \mathrm{MHz}$, $\left.\mathrm{CDCl}_{3}\right): \delta=1.61(\mathrm{~s}, 18 \mathrm{H}, t \mathrm{Bu}), 7.33(\mathrm{t}, 2 \mathrm{H}, \mathrm{Ar}-H), 7.45(\mathrm{~d}, J=$ 7.5, 4H, Ar- $H), 7.46\left(\mathrm{~d}, 2 \mathrm{H}, J=15.8 \mathrm{~Hz},-\mathrm{CH}=\mathrm{CH}_{\mathrm{a}^{-}}\right), 7.71(\mathrm{~d}, J$
$=7.5 \mathrm{~Hz}, 4 \mathrm{H}, \mathrm{Ar}-H), 8.05$ (d, $\left.2 \mathrm{H}, J=15.8 \mathrm{~Hz},-\mathrm{C} H_{\mathrm{b}}=\mathrm{CH}-\right), 8.27$ 60 (s, $\left.2 \mathrm{H}, \mathrm{Py}-H_{3,8}\right), 8.30$ (s, $\left.2 \mathrm{H}, \mathrm{Py}-H_{1,6}\right), 8.49$ (s, $\left.2 \mathrm{H}, \mathrm{Py}-\mathrm{H}_{5,10}\right) \mathrm{ppm}$.

${ }^{13} \mathrm{C}$ NMR $\left(75 \mathrm{MHz}, \mathrm{CDCl}_{3}\right): \delta=32.0,35.5,118.6,122.7,122.8$, $125.2,126.5,126.8,127.8,128.8,129.6,131.0,132.0,134.5$, 137.8, 148.7 ppm. MS (EI): $m / z: 518\left[\mathrm{M}^{+}\right] . \mathrm{C}_{40} \mathrm{H}_{38}$ (518.73): calcd. C 92.62, H 7.38; found C 92.60, H 7.40.

65

Synthesis of (E,E)-2,7-di-tert-butyl-4,9-bis(4-methoxyphenyl ethenyl)pyrene $(\boldsymbol{E}, \boldsymbol{E})-\mathbf{6 b}$ : The Wittig reagent was prepared from triphenylphosphane and 4-methoxybenzyl chloride in dry benzene. To a solution of this Wittig reagent $(2.5 \mathrm{~g}, 6.00 \mathrm{mmol})$ 70 in dry THF $(15 \mathrm{~mL})$ was slowly added $n$-butyllithium in hexane (3.5 mL, $6.00 \mathrm{mmol})$ at $0{ }^{\circ} \mathrm{C}$ under argon. The mixture was stirred for 10 minutes and a solution of 2,7-di-tert-butylpyrene4,9-biscarbaldehyde 3 (371 mg, $1.00 \mathrm{mmol})$ in dry THF $(15 \mathrm{~mL})$ was injected into this mixture under same conditions. The ${ }_{5}$ mixture was heated to room temperature stirring for $6 \mathrm{~h}$ under argon. The mixture was quenched by large amount of water, extracted with dichloromethane $(2 \times 100 \mathrm{~mL})$, the combined extracts were washed with brine and water, dried with $\mathrm{MgSO}_{4}$ and concentrated. The residue was chromatographed over silica 80 gel (Wako C-300, $200 \mathrm{~g}$ ) with hexane as eluent to give lightyellow solids. Recrystallization from hexane afforded $(E, E)-2,7-$ di-tert-butyl-4,9-bis(4-methoxyphenylethenyl)pyrene $\quad(E, E)-\mathbf{6 b}$ (475 mg, 82\%) as light-yellow prisms. M.p. $230{ }^{\circ} \mathrm{C}$; ${ }^{1} \mathrm{H}$ NMR $\left(300 \mathrm{MHz}, \mathrm{CDCl}_{3}\right) \delta=1.60(\mathrm{~s}, 18 \mathrm{H}, t \mathrm{Bu}), 3.89(\mathrm{~s}, 6 \mathrm{H}, \mathrm{OMe})$, ${ }_{85} 7.00(\mathrm{~d}, 4 \mathrm{H}, J=8.7 \mathrm{~Hz}, \operatorname{Ar}-H), 7.35(\mathrm{~d}, 2 \mathrm{H}, J=15.9 \mathrm{~Hz}$, $\mathrm{CH}=\mathrm{C} H-), 7.64(\mathrm{~d}, 4 \mathrm{H}, J=8.7 \mathrm{~Hz}, \operatorname{Ar}-H), 7.91(\mathrm{~d}, 2 \mathrm{H}, J=15.9$ $\mathrm{Hz},-\mathrm{CH}_{\mathrm{b}}=\mathrm{CH}-$ ), 8.24 (s, $\left.2 \mathrm{H}, \mathrm{Py}-H_{3,8}\right), 8.27$ (s, 2H, Py- $\left.H_{1,6}\right), 8.47$ $\left(\mathrm{s}, 2 \mathrm{H}, \mathrm{Py}-\mathrm{H}_{5,10}\right) \mathrm{ppm} .{ }^{13} \mathrm{C} \mathrm{NMR}\left(75 \mathrm{MHz}, \mathrm{CDCl}_{3}\right): \delta=32.0$, $35.4,55.4,114.3,118.4,122.5,122.7,124.3,124.8,128.0,129.6$, $90130.7,131.1,131.4,134.7,148.5,159.5 \mathrm{ppm}$. MS (EI): $\mathrm{m} / \mathrm{z}: 578$ $\left[\mathrm{M}^{+}\right] . \mathrm{C}_{42} \mathrm{H}_{42} \mathrm{O}_{2}$ (578.78): calcd. C 87.16, H 7.31; found C 87.15, $\mathrm{H} 7.32$.

Synthesis of (E,E)-2,7-di-tert-butyl-4,9-bis(3,5-dimethylphenyl ${ }_{95}$ ethynyl)pyrene $(\boldsymbol{E}, \boldsymbol{E})-\mathbf{6 c}$ : The Wittig reagent was prepared from triphenylphosphane and 3,5-dimethylbenzyl bromide in dry benzene. To a solution of this Wittig reagent $(1.4 \mathrm{~g}, 3.00 \mathrm{mmol})$ in dry THF $(15 \mathrm{~mL})$ was slowly added $n$-butyllithium (in hexane) $(1.87 \mathrm{~mL}, 3.00 \mathrm{mmol})$ at $0{ }^{\circ} \mathrm{C}$ under argon. The mixture was 100 stirring for 10 minutes and a solution of 2,7-di-tert-butylpyrene4,9-biscarbaldehyde 3 (372 mg, $1.00 \mathrm{mmol})$ in dry THF $(15 \mathrm{~mL})$ was injected into this mixture under same conditions. After this addition, the mixture was heated to room temperature stirring for $6 \mathrm{~h}$ under argon. The mixture was quenched by large amount of 105 water and extracted with dichloromethane $(2 \times 100 \mathrm{~mL})$. The combined extracts were washed with brine and water, dried with $\mathrm{MgSO}_{4}$ and concentrated. The residue was chromatographed over silica gel (Wako C-300, $200 \mathrm{~g}$ ) with hexane as eluent to give desired compounds (NMR analysis) as yellow solids. 110 Recrystallization from toluene and hexane afforded $(E, E)$-2,7-ditert-butyl-4,9-bis(3,5-dimethylphenylethynyl)pyrene (E,E)-6c (432 mg, 75\%) as yellow solid. M.p. $206{ }^{\circ} \mathrm{C} .{ }^{1} \mathrm{H}$ NMR $(300 \mathrm{MHz}$, $\left.\mathrm{CDCl}_{3}\right): \delta=1.61(\mathrm{~s}, 18 \mathrm{H}, t \mathrm{Bu}), 2.41(\mathrm{~s}, 12 \mathrm{H}, \mathrm{Me}), 7.00(\mathrm{~s}, 2 \mathrm{H}$, $\operatorname{Ar}-H), 7.31$ (s, 4H, Ar-H), 7.34 (d, $\left.2 \mathrm{H}, J=15.9 \mathrm{~Hz},-\mathrm{CH}=\mathrm{CH}_{\mathrm{b}^{-}}\right)$, 1157.80 (d, $\left.2 \mathrm{H}, J=15.9 \mathrm{~Hz},-\mathrm{CH}_{\mathrm{a}}=\mathrm{CH}-\right), 8.26$ (s, 4H, d, Py- $\left.H_{l, 3,6,8}\right)$, 8.48 (s, $\left.2 \mathrm{H}, \mathrm{Py}-H_{5,10}\right)$ ppm. ${ }^{13} \mathrm{C} \mathrm{NMR}\left(75 \mathrm{MHz}, \mathrm{CDCl}_{3}\right): \delta=21.4$, 
32.0, 35.4, 118.6, 122.6, 122.7, 124.8, 125.2, 126.2, 129.6, 131.0, 132.3, 134.7, 137.8, 138.3, 148.6 ppm. MS (EI): $m / z: 574\left[\mathrm{M}^{+}\right]$. $\mathrm{C}_{44} \mathrm{H}_{46}$ (574.84): calcd. C 91.93, H 8.07; found C 91.92, H. 8.08.

\section{${ }_{5}$ Synthesis of (E,E)-2,7-di-tert-butyl-4,10-bis(4-methoxyphenyl} ethenyl)pyrene $(\boldsymbol{E}, \boldsymbol{E})-8$ : Separation of compound pure 2,7-ditert-butyl-4,10-di-formylpyrene by direct method failed by chromatography as well as solvent treatment methods. For this, the mixture $(400 \mathrm{mg})$ of isomers [2,7-di-tert-butylpyrene-4,9-

10 biscarbaldehyde 3 and 2,7-di-tert-butylpyrene-4,10-biscarbaldehyde 4 (1:1)] was treated with 4-methoxybenzyl triphenylphosphonium chloride in the presence of $n$-butyllithum in THF (Wittig reaction) was performed to afford a mixture of the 2,7-di-tert-butyl-4,9-bis(4-methoxyphenylethenyl)pyrene $\mathbf{6 b}$ and

15 2,7-di-tert-butyl-4,10-bis(4-methoxyphenylethenyl)pyrene 8. The careful chromatography with ethyl acetate as eluent afforded the desired compound (E,E)-8 (260 mg, 45\%) as light-yellow prisms. M.p. $220{ }^{\circ} \mathrm{C} .{ }^{1} \mathrm{H}$ NMR $\left(300 \mathrm{MHz}, \mathrm{CDCl}_{3}\right): \delta=1.61(\mathrm{~s}, 9 \mathrm{H}, t \mathrm{Bu})$, $1.65(\mathrm{~s}, 9 \mathrm{H}, t \mathrm{Bu}), 3.89(\mathrm{~s}, 6 \mathrm{H}, \mathrm{OMe}), 7.00(\mathrm{~d}, 4 \mathrm{H}, J=8.8 \mathrm{~Hz}, \mathrm{Ar}-$ $\left.{ }_{20} H\right), 7.34$ (d, $\left.2 \mathrm{H}, J=15.9 \mathrm{~Hz}, \mathrm{Py}-\mathrm{CH}_{\mathrm{b}}=\mathrm{CH}_{a}-\mathrm{Ar}\right), 7.64$ (d, 4H, $J=$ $8.6 \mathrm{~Hz}, \mathrm{Ar}-H$ ), 7.97 (d, 2H, $J=15.9 \mathrm{~Hz}, \mathrm{Py}-\mathrm{CH}_{b}=\mathrm{CH}_{\mathrm{a}}-\mathrm{Ar}$ ), 8.19 (s, $\left.2 \mathrm{H}, \mathrm{Py}-H_{1,3}\right) 8.26$ (s, $\left.2 \mathrm{H}, \mathrm{Py}-H_{6,8}\right), 8.54$ (s, $2 \mathrm{H}$, Pyrene- $\left.H_{5,9}\right)$ ppm. ${ }^{13} \mathrm{C}$ NMR $\left(75 \mathrm{MHz}, \mathrm{CDCl}_{3}\right): \delta=32.0,35.7,55.4,114.3$, $118.7,122.1,123.3,124.5,124.6,124.8,128.1,130.1,130.5$, ${ }_{25} 130.7,131.5,135.1,148.5,149.0,159.5 \mathrm{ppm}$. MS (EI): $\mathrm{m} / \mathrm{z}: 578$ $\left[\mathrm{M}^{+}\right] . \mathrm{C}_{42} \mathrm{H}_{42} \mathrm{O}_{2}$ (578.78): calcd. C 87.16, H 7.31; found. C 87.17, H 7.30.

General procedure for photocyclization: Photo reactor was a 30 cylindrical glass vessel with an immersion well and two tapered joints, one vertical attached with condenser to which argon source was fitted. Another angled for withdrawal and addition of samples. The vessel was flat bottom to allow a magnetic stirring bar to rotate. The immersion well was a double walled pyrex tube 35 cooled by water and containing high pressure quartz $\mathrm{Hg}$-vapour lamp. Argon gas was bubbled through benzene for 20-30 min. and used to dissolved sample and iodine. The dissolved solutions of sample, iodine and propylene oxide were added to the reaction vessel through angled joint and the lamp was turned on. The 40 reaction was carried out under argon atmosphere. Photoreactions were monitored by ${ }^{1} \mathrm{H}$ NMR and iodine color change. After complete irradiation, work included washing with $15 \%$ $\mathrm{Na}_{2} \mathrm{~S}_{2} \mathrm{O}_{3} \cdot \mathrm{H}_{2} \mathrm{O}$ and saturated brime, drying with anhydrous $\mathrm{MgSO}_{4}$, filtering and concentrated to dryness on a rotary ${ }_{45}$ evaporator. The residue obtained was washed either through a short column of silica gel or different solvent systems were used to obtain the pure compounds.

Synthesis of 2,11-di-tert-butyl-tetrabenzo[a,fg,l,op]tetracene ${ }_{50}$ (7a): $(E, E)$-2,7-Di-tert-butyl-4,9-bis(phenylethenyl)pyrene $(E, E)$ 6a $(50.0 \mathrm{mg}, 0.0960 \mathrm{mmol})$ in $230 \mathrm{~mL}$ of benzene was irradiated in presence of $\mathrm{I}_{2}(48.73 \mathrm{mg}, 0.19 \mathrm{mmol})$ and propylene oxide (1.64 mL, $18.83 \mathrm{mmol})$ for $8 \mathrm{~h}$. Work up and washed with hexane: EtOAc (1:1) and followed by excess methanol. ${ }_{55}$ Recystallisation from dichloromethane and hexane affored 2,11di-tert-butyltetrabenzo[a,fg,l,op]tetracene $7 \mathbf{a} \quad(40 \mathrm{mg}, 81 \%)$ as colorless prisms. M.p. $244{ }^{\circ} \mathrm{C} .{ }^{1} \mathrm{H}$ NMR $\left(300 \mathrm{MHz}, \mathrm{CDCl}_{3}\right): \delta=$ $1.66(\mathrm{~s}, 18 \mathrm{H}, t \mathrm{Bu}), 7.62-7.72(\mathrm{~m}, 4 \mathrm{H}, \mathrm{Ar}-H), 8.08$ (d, 2H, $J=8.7$
$\mathrm{Hz}, \operatorname{Ar}-H), 8.14$ (d, 2H, $J=9.0 \mathrm{~Hz}, \operatorname{Ar}-H), 8.89$ (d, 2H, $J=9.0$ $\left.{ }_{60} \mathrm{~Hz}, \operatorname{Ar}-H\right), 8.98$ (s, 2H, Ar- $H$ ), 9.11 (d, 2H, $J=8.4 \mathrm{~Hz}, \operatorname{Ar}-H$ ), $9.18(\mathrm{~s}, 2 \mathrm{H}, \mathrm{Ar}-H) \mathrm{ppm} .{ }^{13} \mathrm{C} \mathrm{NMR}\left(75 \mathrm{MHz}, \mathrm{CDCl}_{3}\right): \delta=31.9$, $35.7,117.8,121.1,123.2,125.3,125.9,126.0,127.9,128.00$, 128.0, 128.1, 128.2, 128.5, 128.7, 130.8, 133.8, 148.0 ppm. MS (EI): $m / z: 514\left[\mathrm{M}^{+}\right] . \mathrm{C}_{40} \mathrm{H}_{34}$ (514.70): calcd. C 93.34, H 6.66; ${ }_{65}$ found C 93.32, H 6.67 .

Synthesis of 2,11-di-tert-butyl-8,17-dimethoxytetrabenzo[a,fg,l,op]tetracene (7b): (E,E)-2,7-Di-tert-butyl-4,9-bis(4methoxyphenylethenyl)pyrene $(E, E)-6 \mathbf{b}(50.0 \mathrm{mg}, 0.09 \mathrm{mmol})$ in ${ }_{70} 200 \mathrm{~mL}$ of benzene was irradiated in presence of $\mathrm{I}_{2}(43.6 \mathrm{mg}$, $0.17 \mathrm{mmol})$ and propylene oxide $(1.54 \mathrm{~mL}, 22.02 \mathrm{mmol})$ for $6 \mathrm{~h}$. Work up and chromatography $\left(30 \% \mathrm{CH}_{2} \mathrm{Cl}_{2}\right.$ in hexane) gave pale yellow solid. Recystallisation from dichloromethane and hexane afforded 2,11-di-tert-butyl-8,17-dimethoxytetrabenzo[a,fg,l,op]75 tetracene $\mathbf{7 b}(34.4 \mathrm{mg}, 70 \%)$ as colorless prisms. M.p. $249{ }^{\circ} \mathrm{C}$. ${ }^{1} \mathrm{H}$ NMR $\left(300 \mathrm{MHz}, \mathrm{CDCl}_{3}\right): \delta=1.66(\mathrm{~s}, 18 \mathrm{H}, t \mathrm{Bu}), 4.02(\mathrm{~s}, 6 \mathrm{H}$, OMe), 7.31 (dd, 2H, $J=2.4,2.4 \mathrm{~Hz}, \operatorname{Ar}-H), 7.99$ (d, $2 \mathrm{H}, J=8.8$ $\mathrm{Hz}, \mathrm{Ar}-\mathrm{H}), 8.07$ (d, 2H, $J=8.8 \mathrm{~Hz}, \operatorname{Ar}-H), 8.53$ (s, 2H, Ar- $H$ ), 8.75 (d, 2H, $J=8.8 \mathrm{~Hz}, \operatorname{Ar}-H), 8.96$ (s, 2H, Ar-H), 9.22 (s, 2H, ${ }_{80} \mathrm{Ar}-H$ ) ppm. ${ }^{13} \mathrm{C}$ NMR $\left(75 \mathrm{MHz}, \mathrm{CDCl}_{3}\right): \delta=32.0$, 35.7, 55.4, $107.8,117.8,117.9,118.9,123.3,124.3,127.20,127.7,128.4$, $128.5,129.0,129.3,129.9,132.0,147.9,158.3$ ppm. MS (EI): m/z: $574\left[\mathrm{M}^{+}\right] . \mathrm{C}_{42} \mathrm{H}_{38} \mathrm{O}_{2}$ (574.75): calcd. C 87.77, $\mathrm{H}$ 6.66; found C 87.78, H 6.65 .

85

Synthesis of 2,11-di-tert-butyl-7,9,16,18-tetramethyltetrabenzo[a,fg,l,op]tetracene (7c): (E,E)-2,7-Di-tert-butyl-4,9-bis(3,5dimethylphenylethynyl)pyrene $(E, E)-6 c(50.0 \mathrm{mg}, 0.09 \mathrm{mmol})$ in $200 \mathrm{~mL}$ of benzene was irradiated in presence of $\mathrm{I}_{2}(43.9 \mathrm{mg}$, 90 $0.17 \mathrm{mmol})$ and propylene oxide $(1.54 \mathrm{~mL}, 22.02 \mathrm{mmol})$ for 12 h. After work up and chromatography $\left(30 \% \mathrm{CH}_{2} \mathrm{Cl}_{2}\right.$ in hexane), The compound thus obtained was further washed with hexane and recrystallized from dichloromethane and hexane to give 2,11di-tert-butyl-7,9,16,18-tetramethyl-tetrabenzo[ $a, f g, l, o p]$ tetracene ${ }_{95}$ 7c (40 mg, 82\%) as white solid. M.p. $261{ }^{\circ} \mathrm{C} .{ }^{1} \mathrm{H}$ NMR (300 $\left.\mathrm{MHz}, \mathrm{CDCl}_{3}\right): \delta=1.58(\mathrm{~s}, 18 \mathrm{H}, t \mathrm{Bu}), 2.36(\mathrm{~s}, 6 \mathrm{H}, \mathrm{Me}), 2.63(\mathrm{~s}$, $6 \mathrm{H}, \mathrm{Me}), 7.37$ (s, 2H, Ar- $H$ ), 7.72 (s, 2H, Ar-H), 8.02 (d, 2H, $J=$ $8.8 \mathrm{~Hz}, \mathrm{Ar}-H), 8.18$ (s, $2 \mathrm{H}, \mathrm{Ar}-H), 8.75$ (d, $2 \mathrm{H}, J=8.8 \mathrm{~Hz}, \mathrm{Ar}-H)$, 8.89 (s, $2 \mathrm{H}, \mathrm{Ar}-H) \mathrm{ppm} .{ }^{13} \mathrm{C}$ NMR $\left(75 \mathrm{MHz}, \mathrm{CDCl}_{3}\right): \delta=21.3$, 100 24.9, 31.9, 35.6, 117.2, 120.3, 121.6, 125.1, 125.8, 127.7, 127.9, $128.1,128.9,129.1,129.5,131.8,134.6,135.5,135.8,147.4$ ppm. MS (EI): $m / z: 570\left[\mathrm{M}^{+}\right] . \mathrm{C}_{44} \mathrm{H}_{42}$ (570.80): calcd. C 92.58, H 7.42; found C 92.59, H 7.40.

${ }_{105}$ Synthesis of 2,11-di-tert-butyl-8,17-dihydroxytetrabenzo [a,fg, l,op]tetracene (7d): A Schlenk flask was charged with methyl ether $7 \mathbf{b}(110.1 \mathrm{mg}, 0.19 \mathrm{mmol})$ and flushed with argon. The material was dissolved in dichloromethane $(10 \mathrm{~mL})$ and $\mathrm{BBr}_{3}$ in 5 $\mathrm{mL}$ dichloromethane, $(0.85 \mathrm{~mL}, 0.85 \mathrm{mmol}, 4.5$ equiv. $)$ was 110 added drop wise. The mixture was stirred at rt. for $6 \mathrm{~h}$. the mixture was diluted with water $(10 \mathrm{~mL})$, extracted with dichloromethane $(3 \times 20 \mathrm{~mL})$. The organic portion was washed with brine and water and finally dried over anhydrous $\mathrm{MgSO}_{4}$ and solvent was evaporated in vacco. The residue was washed 15 with hexane and recrystallized in chloroform and hexane to afford 2,11-di-tert-butyl-8,17-dihydroxytetrabezo $[a, f g, l, o p]$ tetra- 
cene 7d (100 mg 96\%) as white solid. M.p. $254{ }^{\circ} \mathrm{C} .{ }^{1} \mathrm{H}$ NMR $\left(300 \mathrm{MHz}, \mathrm{CDCl}_{3}\right): \delta=1.66(\mathrm{~s}, 18 \mathrm{H}, t \mathrm{Bu}), 5.04(\mathrm{~s}, 2 \mathrm{H}$, $O H), 7.24(\mathrm{~d}, 2 \mathrm{H}, J=2.2 \mathrm{~Hz}, \mathrm{Ar}-H), 7.99(\mathrm{~d}, 2 \mathrm{H}, J=8.6 \mathrm{~Hz}, \mathrm{Ar}-$ H), $8.06(\mathrm{~d}, 2 \mathrm{H}, J=8.8 \mathrm{~Hz}, \operatorname{Ar}-H), 8.51$ (s, 2H, Ar-H), 8.73 (d, $\left.{ }_{5} 2 \mathrm{H}, J=9.0 \mathrm{~Hz}, \operatorname{Ar}-H\right), 8.94$ (s, 2H, Ar- $H$ ), 9.17 (s, 2H, Ar- $H$ ) ppm. ${ }^{13} \mathrm{C}$ NMR $\left(75 \mathrm{MHz}, \mathrm{CDCl}_{3}\right): \delta=31.9,35.6,111.5,116.9$, $117.9,119.0,123.2,124.6,126.8,127.7,128.2,128.4,129.0$, 129.4, 130.3, 132.2, 147.9, 154.2 ppm. MS (EI): $\mathrm{m} / z: 546\left[\mathrm{M}^{+}\right]$. $\mathrm{C}_{40} \mathrm{H}_{34} \mathrm{O}_{2}$ (546.70): calcd. C 87.88, H 6.27; found $\mathrm{C} 87.86, \mathrm{H}$ 106.28 .

Synthesis of 2,11-di-tert-butyl-8,14-dimethoxytetrabenzo[a,fg, l,op]tertacene (9): (E,E)-2,7-Di-tert-butyl-4,10-bis(4-methoxyphenylethenyl)pyrene $(E, E)-8(50.0 \mathrm{mg}, 0.089 \mathrm{mmol})$ in $100 \mathrm{~mL}$

15 of benzene was irradiated in presence of $\mathrm{I}_{2}(43.6 \mathrm{mg}, 0.17 \mathrm{mmol})$ and propylene oxide $(1.54 \mathrm{~mL}, 22.02 \mathrm{mmol})$ for $6 \mathrm{~h}$. Work up and chromatography $\left(30 \% \mathrm{CH}_{2} \mathrm{Cl}_{2} / \mathrm{Hexane}\right)$ gave pale yellow solid or as white crystalline solid. Recentralisation from chloroform and hexane afforded 2,11-di-tert-butyl-8,1420 dimethoxytetrabenzo $[a, f g, l, o p]$ tertacene $9 \quad(34 \mathrm{mg}, 70 \%)$ as colourless prisms. M.p. $256{ }^{\circ} \mathrm{C} .{ }^{1} \mathrm{H} \mathrm{NMR}\left(300 \mathrm{MHz}, \mathrm{CDCl}_{3}\right): \delta=$ $1.58(\mathrm{~s}, 9 \mathrm{H}, t-\mathrm{Bu}), 1.70(\mathrm{~s}, 9 \mathrm{H}, t \mathrm{Bu}), 4.08(\mathrm{~s}, 6 \mathrm{H}, \mathrm{OMe}), 7.32(\mathrm{dd}$, $2 \mathrm{H}, J=2.1,2.1 \mathrm{~Hz}, \mathrm{Ar}-H), 8.00(\mathrm{~d}, 2 \mathrm{H}, J=9.0 \mathrm{~Hz}, \mathrm{Ar}-H), 8.06$ (d, $2 \mathrm{H}, J=8.8 \mathrm{~Hz}, \mathrm{Ar}-H$ ), 8.64 (s, 2H, Ar- $H$ ), 8.75 (d, 2H, $J=8.8$ $\left.{ }_{25} \mathrm{~Hz}, \mathrm{Ar}-H\right), 9.02$ (s, 2H, Ar-H), 9.22 (s, $\left.2 \mathrm{H}, \mathrm{Ar}-H\right) \mathrm{ppm} .{ }^{13} \mathrm{C}$ NMR $\left(75 \mathrm{MHz} \mathrm{CDCl}_{3}\right): \delta=32.0,35.5,55.5,107.9,118.0,119.0$, $199.1,122.5,123.7,124,7,127.3,127.6,128.0,128.9,129.0$, 129.2, 130.0, 132.1, 146.5, 149.0, 158.3 ppm. MS (EI): $m / z: 574$ $\left[\mathrm{M}^{+}\right] . \mathrm{C}_{42} \mathrm{H}_{38} \mathrm{O}_{2}$ (574.75): calcd. C 87.77, $\mathrm{H}$ 6.66; found $\mathrm{C} 87.76$, $30 \mathrm{H} 6.68$.

\section{Crystal data and refinement details for $7 b, 7 c$ and 9}

Diffraction data were collected using a Bruker SMART APEX II CCD diffractometer using narrow frames. ${ }^{34}$ Diffraction data for 7b, 7c and 9 were collected with synchrotron radiation at the 35 ALS, Station 11.3.1. Data were corrected for absorption on the basis of symmetry equivalent and repeated data and for Lp effects. The structures were solved by direct methods (charge flipping for 9) and refined on $F^{2}$ using all data. ${ }^{35} \mathrm{H}$ atoms were constrained in a riding model. There are two and four molecules 40 in the asymmetric units of $\mathbf{7 b}, \mathbf{7 c}$ and $\mathbf{9}$ respectively. Further details can be found in Table S1 and ref. 21.

Supporting information (See also the footnote on the first page of this article): ${ }^{1} \mathrm{H} /{ }^{13} \mathrm{C}$ NMR spectra of $\mathbf{6 a}-\mathbf{c}, 7 \mathbf{7 a}-\mathbf{d}, \mathbf{8}$ and $\mathbf{9}$, TGA curves of $\mathbf{7 a - c}$ and $\mathbf{9}$, packing duagram of $\mathbf{7 b}, \mathbf{7 c}$ and $\mathbf{9}$, 45 normalised emission spectra of $7 \mathbf{a}-\mathbf{c}$ and $\mathbf{9}$ recorded in thin neat films, cyclic voltammogram (CV) of $\mathbf{7 a - c}$ and $\mathbf{9}$, and summary of crystal data of $7 \mathbf{b}, 7 \mathbf{c}$ and $\mathbf{9}$.

\section{Acknowledgements}

We would like to thank CANON Company for financial support ${ }_{50}$ and the EPSRC UK National Crystallography Service at Southampton University and Daresbury Laboratory. This work was performed under the Cooperative Research Program of "Network Joint Research Center for Materials and Devices (Institute for Materials Chemistry and Engineering, Kyushu
55 University)". The Advanced Light Source is supported by the Director, Office is Science, Office of Basic Energy Science, of the U.S. Department of Energy under Contract No. DE-AC02$05 \mathrm{CH} 00231$.

\section{References}

601 (a) M. S. Newman and D. Lednicer, J. Am. Chem. Soc., 1956, 78, 4765-4774; (b) A. Rajca and M. Miyasaka, Synthesis and Characterisation of Novel Chiral Conjugated Materials. Functional Organic Material; (c) A. Urbano, Angew. Chem., 2003, 115, 4116-4119.

652 (a) R. H. Martin, Angew. Chem. Int. Ed., 1974, 13, 649-660; (b) D. Z. Wang and T. J. Katz, J. Org. Chem., 2005, 70, 8497-8502.

3 (a) T. Verbist, S. Sioncke, A. Persoons, L. Vyklicky and T. J. Katz, Angew. Chem. Int. Ed., 2002, 41, 3882-3884; (b) C. Nuckolls, R. Shao, W. G. Jang, N. A. Clark, D. M. Walba and T. J. Katz, Chem. Mater., 2002, 14, 773-776.

4 (a) Y. Dai and T. J. Katz, J. Org. Chem., 1997, 62, 1274-1285; (b) J. M. Fox and D. Lin, J. Org. Chem., 1998, 63, 2031-2038.

5 (a) B. Laleu, P. Mobian, C. Herse, B. W. Lauresen, G. Hopfgartner and G. Berandinelli, Angew. Chem. Int. Ed., 2005, 44, 1879-1883; (b) M. T. Reetz, S. Sostmann, Tetrahedron 2001, 57, 2515-2520.

6 (a) Y. Xu, X. Y. Zhang, H. Sugiyama, T. Umano, H. Osuga and K. Tanaka, J. Am. Chem. Soc., 2004, 126, 6566-6567; (b) I. Sato, K. Yamashima, K. Kadowaki, J. Yamamoto, T. Shibata and K. Soal, Angew. Chem. Int. Ed., 2001, 40, 1096-1098; (c) S. D. Dreher, T. J.

80 Katz, K.-C. Lam and A.L. Rheingold, J. Org. Chem., 2000, 65, 815-822; (d) H. Sugiura, Y. Takahira and M. Yamaguchi, J. Org. Chem., 2005, 70, 5698-5708; (e) E. Murguly, R. McDonald and N. R. Brandra, Org. Lett., 2000, 2, 3169-3172.

7 (a) S. Sahasithiwat, T. Mophuang, L. Menbangpung, S. Kamtonwong and T. Sooksimuang, Synth. Met., 2010, 160, 1148-1152; (b) L. Shi, Z. Liu, G. Dong, L. Duan, Y. Qiu, J. Jia, W. Guo, D. Zhao, D. Cui and X. Tao, Chem. Eur. J., 2012, 18, 8092-8099.

8 (a) H. A. Staab, M. Diehm and C. Kriger, Tetrahedron Lett., 1994, 35, 8357-8360; (b) M. Flammang-Barbieux, J. Nasielski and R. H.

90 Martin, Tetrahedron Lett., 1967, 8, 743-744; (c) R. H. Martin, M. Flammang-Barbieux, J. P. Cosyn and M. Gelbcke, Tetrahedron Lett., 1968, 31, 3507-3510; (d) D. C. Harrowven, M. I. T Nunn and D. R. Fenwick, Tetrahedron Lett., 2002, 43, 3189-3191; (e) Y. Ogawa, T. Ueno, M. Karikomi, K. Seki, K. Haga and T. Uyehara, Tetrahedron Lett., 2002, 43, 7827-7829; (f) J. N. Moorthy, P. Venkatakrishnan, S. Sengupta and M. Baidya, Org. Lett., 2006, 8, 4891-4894; (g) R. E Abed, B. Hassine, J.-P. Genet, M. Gorsane and A. Marinetti, Eur. J. Org. Chem., 2004, 1517-1522; (h) D. C. Harrowven, I. L. Guy and L. Nanson, Angew. Chem. Int. Ed., 2006, 45, 2242-2245; (i) F. Aloui and C. B. Hassine, Tetrahedron Lett., 2009, 50, 4321-4323.

9 L. Liu, B. Yang, T. J. Katz and M. K. Poindexter, J. Org. Chem., 1991, 56, 3769-3775.

10 See examples of benzene-fused helicenes: (a) T. Verbiest, S. V. Elshocht, M. Kauranen, L. Hellemans, J. Snauwaert, C. Nuckolls, T. J. Katz and A. Persoons, Science 1998, 282, 913-915; (b) T. J. Katz, Angew. Chem. Int. Ed., 2000, 39, 1921-1923; (c) T. Verbiest, S. Sioncke, A. Persoons, L. Vyklick $\square$ and T. J. Katz, Angew. Chem. Int Ed., 2002, 41, 3882-3884; (d) A. Grandbois and S. K. Collins, Chem. Eur. J., 2008, 14, 9323-9329.

1011 See examples of thiophene-fused helicenes: (a) A. Rajca, H. Wang, M. Pink and S. Rajca, Angew. Chem. Int. Ed., 2000, 39, 4481-4483; (b) A. Rajca, H. Wang, M. Pink and S. Rajca, Angew. Chem. Int. Ed., 2000, 112, 4655-4657; (c) A. Rajca, M. Miyasaka, M. Pink, H. Wang and S. Rajca, J. Am. Chem. Soc., 2004, 126, 15211-15222; (d) M. Miyasaka, A. Rajca, M. Pink and S. Rajca, J. Am. Chem. Soc., 2005, 127, 13806-13807; (e) J. K. Zak, M. Miyasaka, S. Rajca, M. Lapkowski and A. Rajca, J. Am. Chem. Soc., 2010, 132, 3246-3247.

12 See examples of benzothiophene-fused helicenes: (a) K. Tanaka, H. Suzuki and H. Osuga, J. Org. Chem., 1997, 62, 4465-4470; (b) T. Caronna, R. Sinisi, M. Catellani, L. Malpezzi, S. V. Meille and A. Mele, Chem. Commun., 2000, 15, 1139-1140; (c) T. Caronna, M. Catellani, S. Luzzati, L. Malpezzi, S. V. Meille, C. Ritchter and R. 
Sinisi, Chem. Mater., 2001, 13, 3906-3914; (d) T. Iwasaki, Y. Kohinata and H. Nishide, Org. Lett., 2005, 7, 755-758.

13 (a) F. A. Vingiello and P. D. Henson, J. Org. Chem., 1965, 30, 2842-2845; (b) R. J. Hayward, A. C. Hopkinson and C. C. Laznoff, Tetrahedron 1972, 28, 439-447; (c) R. H. Martin, J. Jespers and N. Defay, Tetrahedron Lett., 1975, 16, 1093-1096.

14 A. Paudel, J.-Y. Hu and T. Yamato, J. Chem. Res., 2008, 457-460.

15 (a) G. Portella, J. Poater, J. M. Bofill, P. Alemany and M. Solà, J. Org. Chem., 2005, 70, 2509-2521; (b) C. Brulé, K. K. Laali, T. Okazaki and M. K. Lakshman, J. Org. Chem., 2007, 72, 3232-3241.

16 T. Föster and K. Z. Kasper, Electrochem., 1955, 59, 976-982.

17 (a) F. M. Winnik, Chem. Rev., 1993, 93, 587-614; (b) A. Okamoto, K. Kanatani and I. Saito, J. Am. Chem. Soc., 2004, 126, 4820-4827; (c) S. K. Kim, J. H. Bok, R. A. Bartsch, J. Y. Lee and J. S. Kim, Org. Lett., 2005, 7, 4839-4842.

18 (a) T. Yamato, A. Miyazawa and M. Tashiro, J. Chem. Soc., Perkin Trans. 1, 1993, 24, 3127-3137; (b) M. Tashiro and T. Yamato, J. Am. Chem. Soc., 1982, 104, 3707-3710; (c) T. Yamato and J.-Y. Hu, J. Chem. Res., 2006, 762-765.

2019 M. Moyle and E. Ritchie, Aust. J. Chem., 1958, 11, 211-224.

20 J.-Y. Hu, A. Paudel and T. Yamato, J. Chem. Res., 2009, 109-113.

21 CCDC-778372 (7b), 870212 (7c) and 870213 (9) contains the supplementary crystallographic data for this paper. These data can be obtained free of charge from The Cambridge Crystallographic Data

25 Centre via www.ccdc.cam.ac.uk/data_request/cif.

22 M. K. Lakshman, L. P. Kola, S. Caturvedi, H. Saugier, H. J. C. Yeh, P. J. Glusker, H. L. Carrell, K. A. Katz, C. E. Afshar, W.-M. Dashwood, G. Kenniston and W. M. Baird, J. Am. Chem. Soc., 2000, 122, 12629-12636.

3023 M. Pope, C. E. Swenberg, Electronic Processes in Organic Crystals and Polymers, 2nd edition, Oxford University Press, Oxford 1999, $48-53$.

24 K. Kalyanasundaram and J. K. Thomas, J. Am. Chem. Soc., 1977, 99, 2039-2044.

3525 (a) J.-Y. Hu, M. Era, M. R. J. Elsegood and T. Yamato, Eur. J. Org. Chem., 2010, 72-79; (b) J.-Y. Hu, X.-L. Ni, X. Feng, M. Era, M. R. J. Elsegood, S. J. Teat and T. Yamato, Org. Biomol. Chem., 2012, 10, 2255-2262.

26 D. Wasserfallen, M. Kastler, W. Pisula, W. A. Hofer, Y, Fogel, Z. Wang and K. Müllen, J. Am. Chem. Soc., 2006, 128, 1334-1339.

27 S. Chen, X. Xu, Y. Liu, G. Yu, X. Sun, W. Qiu, Y. Ma and D. Zhu, Adv. Funct. Mater., 2005, 15, 1541-1546.

28 (a) A. Harriman, M. Hissler and R. Ziessel, Phys. Chem. Chem. Phys., 1999, 1, 4203-4211; (b) A. C. Benniston, A. Harriman, S. L. Howell, C. A. Sams and Y.-G. Zhi, Chem. Eur. J., 2007, 13, 4665-4674.

29 K. D. Singer, J. E. Sohn and S. J. Lalama, Appl. Phys. Lett., 1986, 49 248-250.

30 (a) C. W. Tang, S. A. VanSlyke and C. H. Chen, J. Appl. Phys., 1989 65, 3610-3606; (b) M.-T. Lee, H.-H. Chen, C.-H. Liao and C.-H. s0 Tsai, Appl. Phys. Lett., 2004, 85, 3301-3303.

31 Y. Li, J. Ding, M. Day, Y. Tao, J. Lu and M. D'iorio, Chem. Mater., 2004, 16, 2165-2173.

32 (a) M. D. de Leeuw, M. M. J. Simenon, A. B. Brown and R. E. F. Einerhand, Synth. Met., 1997, 87, 53-59; (b) R. Cervini, X.-C. Li, G.

55 W. C. Spencer, A. B. Holmes, S. C. Moratti and R. H. Friend, Synth Met., 1997, 84, 359-360.

33 P. Sonar, M. S. Son, Y. H. Cheng, J. T. Henssler and A. Sellinger, Org. Lett., 2010, 12, 3292-3295.

34 APEX II and SAINT (2006) software for diffractometers, Bruker AXS Inc., Madison, WI, USA.

35 G. M. Sheldrick, Acta Crystallogr., Sect. A: Found. Crystallogr., 2008, A64, 112-120. 